\title{
St Thomas' Hospital polarizing blood cardioplegia improves hemodynamic recovery in a porcine model of cardiopulmonary bypass
}

David Santer, MD, PhD, ${ }^{a}$ Anne Kramer, DVM, ${ }^{a}$ Attila Kiss, MSc, PhD, ${ }^{a}$ Klaus Aumayr, MD, PhD, ${ }^{b}$ Matthias Hackl, PhD, ${ }^{\mathrm{c}}$ Stefan Heber, MD, PhD,${ }^{\mathrm{d}}$ David J. Chambers, PhD, ${ }^{\mathrm{e}}$ Seth Hallström, PhD, ${ }^{\mathrm{f}}$ and Bruno K. Podesser, MD $^{\mathrm{a}}$

\section{ABSTRACT}

Objective: Cardiac surgery demands highly effective cardioprotective regimens. We previously demonstrated improved cardioprotection with "polarized" compared with "depolarized" arrest. This study uses a clinically relevant porcine model of cardiopulmonary bypass to compare the efficacy of blood-based St Thomas' Hospital polarizing cardioplegia (STH-Pol-B) with blood-based St Thomas' Hospital hyperkalemic cardioplegia (STH2-B).

Methods: Pigs were monitored and subjected to normothermic cardiopulmonary bypass, cardiac arrest via antegrade cold $\left(4^{\circ} \mathrm{C}\right)$ blood cardioplegia (STH2-B, control group: $\mathrm{n}=6$ or STH-Pol-B, study group: $\mathrm{n}=7$ ), and global ischemia (60 minutes) followed by on-pump reperfusion (60 minutes) and subsequent off-pump reperfusion (90 minutes). At termination, tissue samples were taken for analysis of high-energy phosphates, ultrastructure, and microRNAs. The primary endpoint of this study was creatine kinase-muscle/brain release during reperfusion.

Results: Creatine kinase-muscle/brain was comparable in both groups. After pigs were weaned from cardiopulmonary bypass, hemodynamic parameters such as mean arterial pressure $(P=.007)$, left ventricular systolic pressure $(P<.001)$, external heart work $(P=.012)$, stroke volume $(P=.015)$, as well as $\mathrm{dp} / \mathrm{dt}_{\max }$ $(P=.027)$, were improved with polarizing cardioplegia. Wedge pressure was significantly lower in the study group $(P<.01)$. Energy charge was comparable between groups. MicroRNA-708-5p was significantly lower $(P=.019)$ and microRNA-122 expression significantly $(P=.046)$ greater in STH-Pol-B hearts.

Conclusions: Polarized cardiac arrest offers similar myocardial protection and enhances functional recovery in a porcine model of cardiopulmonary bypass. Differential expression of microRNAs may indicate possible new ischemia-reperfusion markers. These results confirm the noninferiority and potential of polarized versus depolarized arrest. (J Thorac Cardiovasc Surg 2019;158:1543-54)

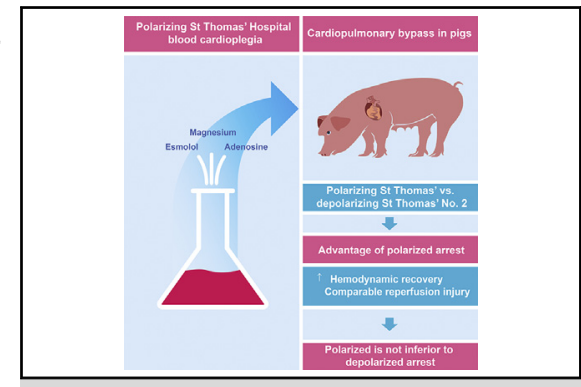

Polarized is not inferior to depolarized arrest in cardiopulmonary bypass in pigs.

\section{Central Message}

In cardiopulmonary bypass in pigs, St Thomas Hospital polarizing blood cardioplegia shows similar ischemia-reperfusion injury and improves hemodynamic recovery compared with depolarizing cardioplegia.

\section{Perspective}

St Thomas' Hospital polarizing blood cardioplegia shows superiority in hemodynamics and noninferiority in biochemical parameters compared with standard St Thomas' No. 2 blood cardioplegia in a porcine model of cardiopulmonary bypass. Polarized arrest has the potential to improve myocardial protection in cardiac surgery.

See Commentaries on pages 1555 and 1557.
In cardiac surgery, the number of elderly and multimorbid patients has dramatically increased over the last 20 years ${ }^{1}$ and is associated with elevated perioperative mortality. ${ }^{2}$

\footnotetext{
From the a Ludwig Boltzmann Cluster for Cardiovascular Research at the Center for Biomedical Research, ${ }^{\mathrm{b}}$ Clinical Institute for Pathology, AKH Wien, and ${ }^{\mathrm{d}}$ Institute of Physiology, Center for Physiology and Pharmacology, Medical University of Vienna, Vienna, Austria; ${ }^{\mathrm{c} T A m i R N A} \mathrm{GmbH}$, Vienna, Austria; ${ }^{\mathrm{e}}$ Cardiac Surgical Research, The Rayne Institute (King's College London), Guy's and St Thomas' NHS Foundation Trust, St Thomas' Hospital, London, United Kingdom; and ${ }^{\mathrm{f}}$ Physiological Chemistry, Otto Loewi Research Center, Medical University of Graz, Graz, Austria.

Funded by an Award from King's College London and continuous funding of the Ludwig Boltzmann Society (grant number REM 2013/16) and the Medical Scientific Fund of the Mayor of the City of Vienna Foundation (Buergermeisterfonds, project number 17056).
}

Therefore, constant efforts to improve intraoperative myocardial protection are essential to optimize postoperative outcome.

\footnotetext{
Received for publication May 3, 2018; revisions received Oct 25, 2018; accepted for publication Nov 19, 2018.

Address for reprints: Bruno K. Podesser, MD, Center for Biomedical Research, Medical University of Vienna, Waehringer Guertel 18-20, 1Q, 1090 Vienna, Austria (E-mail: bruno.podesser@meduniwien.ac.at), and Seth Hallström, PhD, Division of Physiological Chemistry, Otto Loewi Research Center, Medical University of Graz, 27 Graz, Neue Stiftingtalstrasse 6, 8010 Graz, Austria (E-mail: seth. hallstroem@medunigraz.at)

$0022-5223 / \$ 36.00$

Copyright (C) 2018 by The American Association for Thoracic Surgery

https://doi.org/10.1016/j.jtcvs.2018.11.104
} 

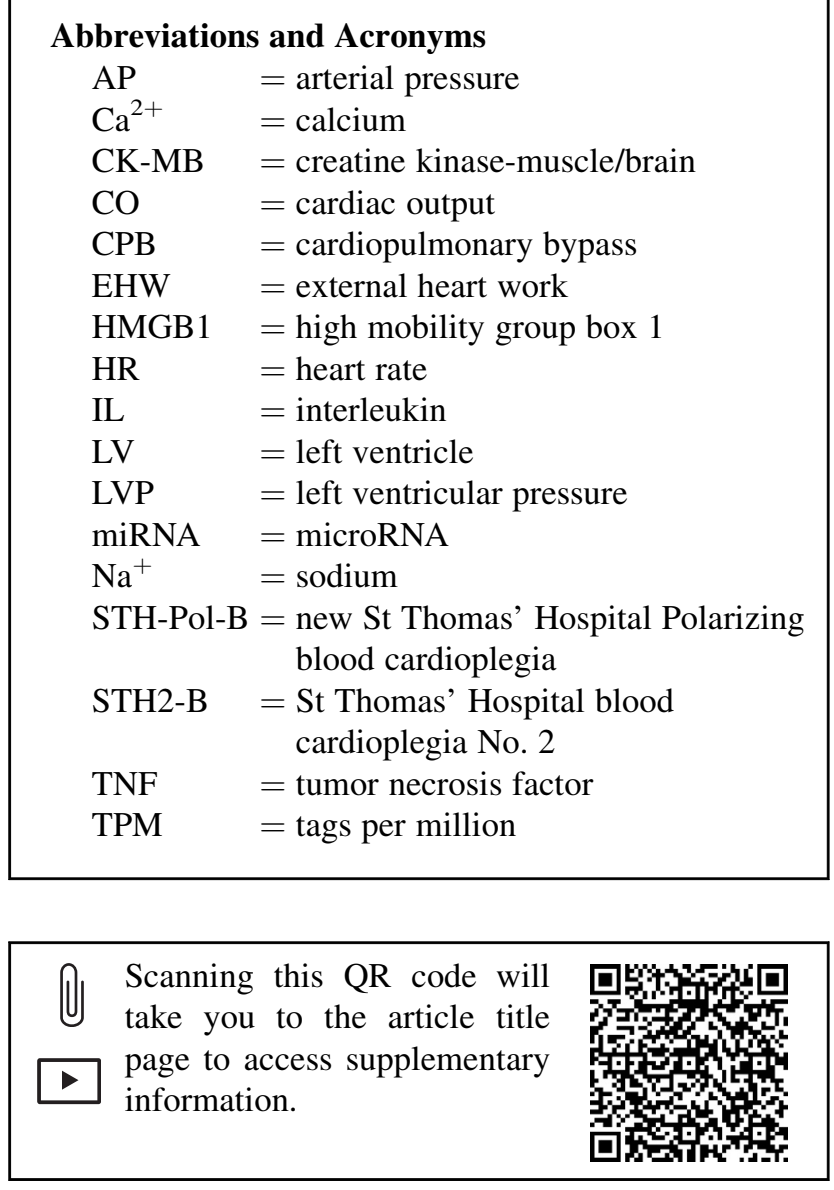

Standard (depolarizing) St Thomas' Hospital cardioplegic solution No. 2 (STH2), with a potassium concentration of $16 \mathrm{mmol} / \mathrm{L}$, magnesium of $16 \mathrm{mmol} / \mathrm{L}$, and calcium $\left(\mathrm{Ca}^{2+}\right)$ of $1.2 \mathrm{mmol} / \mathrm{L}$, became one of the most widely used crystalloid cardioplegic solutions worldwide. ${ }^{3}$ However, hyperkalemic cardioplegic solutions have a narrow extracellular concentration window (potassium between 10 and $30 \mathrm{mmol} / \mathrm{L}$ ), which can lead to intracellular sodium $\left(\mathrm{Na}^{+}\right)$accumulation via the noninactivated $\mathrm{Na}^{+}$ "window-current," with subsequent elevation in myocyte $\mathrm{Ca}^{2+}$ loading, contracture, and cell death. ${ }^{4}$

A search for a safer means of inducing arrest showed the efficacy of high $(\mathrm{mmol} / \mathrm{L})$ concentrations of esmolol. ${ }^{5}$ The arrest characteristics of esmolol act via $\mathrm{Ca}^{2+}$-channel and $\mathrm{Na}^{+}$-channel blockade. ${ }^{6}$ Recently, Aass and colleagues ${ }^{7}$ demonstrated the efficacy of this new blood-based St Thomas' Hospital polarized cardioplegia (STH-Pol-B) in a cardiopulmonary bypass (CPB) model in pigs. They pointed out the benefits of polarized arrest on the energy status and cardiac index during late ischemia and the early phase of reperfusion. The primary aim of the present study was to describe the effects of low-dose STH-Pol-B on coronary enzyme release (coronary creatine kinase-muscle/brain [CK-MB], troponin I) during reperfusion. We hypothesized that polarized arrest was noninferior to conventional depolarized arrest. Therefore, in a porcine CPB model, the new blood-based polarizing cardioplegic solution (STH-Pol-B) was compared with standard depolarizing blood-based STH-2, with a view of providing detailed information on cardiac enzyme release, metabolism, hemodynamic functional recovery, and ultrastructure. In addition, our study provides, for the first time, data on the expression of noncoding RNAs, such as myocardial microRNAs (miRNA) in left ventricular tissue samples following CPB. These results may contribute a better understanding of ischemia-reperfusion injury following $\mathrm{CPB}$ and provide an indication of whether targeting miRNAs might be a potential novel therapeutic approach to limit myocardial ischemia-reperfusion injury.

\section{METHODS \\ Animals}

Female pigs ( $n=14$, Austrian Landrace) were housed at the Center for Biomedical Research, Medical University of Vienna, Austria. Pigs arrived 1 week before experiments for acclimatization and were fed with standard diet twice a day (ssniff GmbH, Soest, Germany) and water ad libitum. The experiments were approved by the Animal Ethics Committee of the Medical University of Vienna (GZ: 66.009/0171-II/3b/2011) and the Austrian Ministry of Science and Technology. All animals received humane care in compliance with the Federation of European Laboratory Animal Science Associations. One experiment had to be stopped during CPB due to an uncontrollable bleeding after aortic cannulation; therefore, 13 pigs were included into the study.

\section{Protocol}

Animals were prepared for $\mathrm{CPB}$ as described in the Appendix E1. After baseline measurements, CPB was initiated, the aorta crossclamped, and hearts were arrested with antegrade, blood-based cold STH-Pol-B $(n=7)$ or STH2-B $(n=6)$. Sixty minutes of ischemia were followed by 60 minutes of on-pump reperfusion (sampling time points: 1, 5, 15, 30, 60 minutes; Figure 1), and another 90 minutes of off-pump reperfusion (time points: 90, 120, and 150 minutes; Figure 1). After venous and arterial decannulation protamine $(300 \mathrm{IU} / \mathrm{kg}$ ) was administered. To maintain systolic blood pressure above $70 \mathrm{~mm} \mathrm{Hg}$ and hemoglobin greater than $6 \mathrm{mg} / \mathrm{dL}$, both volume substitution and continuous noradrenaline infusion were administered. Samples from the left anterior wall were harvested for determination of high-energy phosphates, miRNAs, histology, and electron microscopy. The pigs were humanely killed with high-dose pentobarbital.

\section{Cardioplegic Solutions}

The basic composition of STH-Pol-B was $1.0 \mathrm{mmol} / \mathrm{L}$ esmolol (Baxter, Vienna, Austria), $0.5 \mathrm{mmol} / \mathrm{L}$ adenosine (Sigma-Aldrich, St Louis, Mo), and $10.0 \mathrm{mmol} / \mathrm{L}$ magnesium gluconate (G.L. Pharma GmbH, Lannach, Austria) in a total volume of $1000 \mathrm{~mL}$ of Ringer's solution. Pig blood $(500 \mathrm{~mL})$ was mixed with this crystalloid solution $(1: 2$; total volume: $1500 \mathrm{~mL}$ ) immediately before administration. STH2 ( NaCl: $110.0 \mathrm{mmol} /$ $\mathrm{L}, \mathrm{NaHCO}_{3}: 10.0 \mathrm{mmol} / \mathrm{L}, \mathrm{KCl}: 16.0 \mathrm{mmol} / \mathrm{L}, \mathrm{MgCl}_{2}: 16.0 \mathrm{mmol} / \mathrm{L}$; $\mathrm{CaCl}_{2}: 1.2 \mathrm{mmol} / \mathrm{L}$ ) was provided by the hospital pharmacy of the General Hospital Linz, Austria, and was mixed (1:2; total volume: $1500 \mathrm{~mL})$ with $500 \mathrm{~mL}$ of pig blood. After aortic crossclamping, $1000 \mathrm{~mL}$ of the respective blood cardioplegia was infused with a pressure of $60 \mathrm{~mm} \mathrm{Hg}$ and a temperature of $4^{\circ} \mathrm{C}$; after 30 minutes of ischemia, an additional $500 \mathrm{~mL}$ of the 


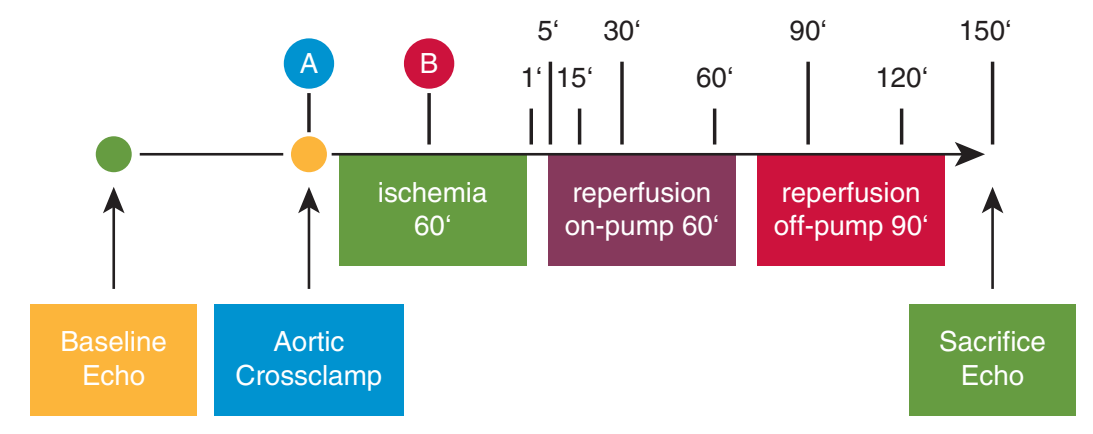

A First dose of STH-Pol-B or STH2-B

B Second dose of STH-Pol-B or STH2-B

FIGURE 1. Experimental protocol. After baseline hemodynamic and echocardiography measurements, aortic crossclamping was performed followed by 60 minutes of ischemia, 60 minutes of on-pump and, finally, 90 minutes of off-pump reperfusion. Before the pigs were humanely killed, echocardiography was repeated. A, Administration of the first dose of STH-Pol-B or STH2-B (1000 mL after aortic crossclamping). B, Administration of the second dose of STH-Pol-B or STH2-B during ischemia $(500 \mathrm{~mL})$. Pig blood was mixed with the crystalloid solution in a ratio of 1:2—see the Methods. The indicated times refer to sampling points. STH-Pol-B, New St Thomas' Hospital Polarizing blood cardioplegia; STH2-B, St Thomas' Hospital blood cardioplegia No. 2.

cardioplegia solutions was infused. The final molar concentrations of both cardioplegic solutions are presented in Table E1.

\section{Hemodynamic Evaluation}

Heart rate (HR), arterial pressure (AP), right atrial pressure, left ventricular pressure (LVP), and cardiac output (CO) were continuously measured. Coronary flow in the left anterior descending coronary artery and wedge pressure were recorded at baseline (before start of $\mathrm{CPB}$ ) and at 1, 5, 15, $30,60,90,120$, and 150 minutes of reperfusion. Echocardiographic evaluation - ejection fraction, fractional shortening — was performed at baseline and before sacrifice. External heart work (EHW) was calculated by $(\mathrm{CO} \times$ systolic LVP) for each time point.

\section{Biochemical Analyses}

CK-MB, Troponin I, Lactate, Oxygen Consumption, Malondialdehyde Assessment, and High-Energy Phosphates.

Energy status are described in the Appendix E1.

\section{Histology}

Histology and electron microscopy are described in the Appendix E1.

\section{MiRNA and Quantitative Polymerase Chain \\ Reaction Analyses}

MiRNA and quantitative polymerase chain reaction analyses are described in detail in the Appendix E1.

\section{Statistical Analysis}

Graphs were generated with GraphPad Prism (7.04; GraphPad Software, La Jolla, Calif), and statistical analysis was performed using IBM SPSS Statistics 24 (IBM Corp, Armonk, NY). Sample size calculation was based on the primary outcome variable and was performed with the sample size calculator available at http://clincalc.com/Stats/SampleSize. aspx. Based on a previous study in rats by Fujii and Chambers, ${ }^{8}$ we expected a standard deviation of 3 units. We defined a minimally relevant group difference as 5 units. With a power of $80 \%$, accepting the probability of a type I error of $5 \%, 6$ animals per group were needed. As a safety margin, we aimed for 7 pigs per group. One animal had to be excluded due to a cannulation problem.

To estimate the difference between animals receiving STH-Pol-B or STH2-B regarding the dependent variables, mixed linear models were applied. First, data were inspected visually for approximate normal distribution in both groups at all time points, and right-skewed data were $\log 10$ transformed. Data are given as mean and standard deviation in case normal distribution could be assumed, right-skewed data a given as geometric mean with its $95 \%$ confidence interval. The factor "group" with the 2 levels STH-Pol-B and STH2-B was specified as a fixed between-subjects factor, the factor "time" with the respective time points as levels was specified as fixed within-subjects factor. Further, each pig was included as a level of a random factor. To adjust the models for pretreatment differences, the baseline values were included as a covariate. The models were estimated using the restricted maximum likelihood method. After we chose adequate covariance-structures based on the smallest Akaike information criterion value, a time by group interaction was tested. In case of a significant interaction, contrasts were used to estimate group differences at each time point. Otherwise, the interaction term was dropped from the model, and the main effect of "group" was interpreted as group difference that applies to all time points. All reported $P$ values are result of 2 -sided tests. $P$ values of .05 or less were considered significant.

Pearson correlation coefficient was used to analyze the correlation between troponin I and miR-122. Binary events were compared with Fisher exact test. Metric values are presented as absolute values or as mean \pm standard deviation, ordinal variables are shown as median with interquartile range. A $P$ value of $<.05$ was considered significant. For miRNA analysis, differentially expressed miRNAs were identified based on the classic statistical functions available under publicly available R-package EdgeR. ${ }^{9}$ We used the nontransformed miRNA read counts for analysis under EdgeR. Initially, to account for technical factors influencing miRNA detection, EdgeR was used for adjusting to effects resulting from varying sequencing depths through normalization to the total library size (automatic function). Next, to account for varying RNA composition, a model-based scale normalization was performed for every sample by calculating the trimmed means of M-values. For differential expression analysis, the glm functions available under EdgeR were used together with likelihood ratio tests. The obtained $P$ values were corrected for multiple testing by applying the Benjamini-Hochberg method on $P$ values to control false-discovery rate. Arterial CK-MB release was defined as primary endpoint; therefore, we took mean values from Fujii and Chambers and aimed for a comparable reduction in the STH-Pol-B versus STH2-B group. All secondary outcome measures were not adjusted for multiplicity because of the exploratory nature of this study and have to be interpreted accordingly. Electron microscopy data were analyzed using a MannWhitney $U$ test with an exact $P$ value due to limited sample size. The 
damage categories no, slight, moderate, severe, and irreversible damage were coded as $0,1,2,3$, and 4 , respectively, allowing for coding of intermediate evaluations as "slight to moderate" corresponding to 2.5 .

\section{RESULTS}

\section{Animal Characteristics}

Baseline values are depicted in Table 1. Thirteen pigs were included in the study (STH-Pol-B: $\mathrm{n}=7,52 \pm 4 \mathrm{~kg}$, STH2-B: $\mathrm{n}=6,62 \pm 4 \mathrm{~kg} ; P=.1)$. Time to asystole was similar in both groups (STH-Pol-B: $154 \pm 65$ seconds vs STH2-B: $170 \pm 36$ seconds; $P=.84$ ). All hearts were arrested during the first application of cardioplegia. Five STH-Pol-B and three STH2-B pigs had ventricular fibrillation during early reperfusion. Numbers of applied defibrillations were comparable in both groups $(P=.071$; Figure E1). None of the pigs required temporary pacemaker stimulation during reperfusion.

\section{Hemodynamic Data}

Baseline hemodynamics are depicted in Table E2. There were no differences between groups for any parameter at baseline. Ejection fraction (STH-Pol-B vs STH2-B: $58 \pm 4$ vs $63 \pm 2 \% ; P=.46)$ and fractional shortening (STH-Pol-B vs STH2-B: $31 \pm 2$ vs $33 \pm 2 \% ; P=.50$ ) were comparable at baseline and at the end of the experiment. During reperfusion, HR $(P=.18)$, systolic AP $(P=.32)$, right atrial pressure $(P=.296)$, CO $(P=.282)$, left ventricular end-diastolic pressure $(P=.411)$, and noradrenaline support $(P=.702$; Table 2 and Figure E2) were comparable between both groups, whereas the following parameters were significantly increased in STH-Pol-B versus STH2-B: diastolic AP $(P=.032)$, mean arterial pressure $(P=.007$; Figure 2, $A)$, systolic LVP $(P<.001$; Figure $2, B)$, stroke volume $(P=.015$; Figure 2, $C)$, external heart work (EHW; $P=.012$; Figure 2, $D)$, left ventricular end systolic pressure $(P=.01$, Figure $3, A)$, and coronary flow $(P=.03$; Figure 3, $B)$. Wedge pressure was markedly lower in STH-Pol-B after weaning $(P=.014$; Figure $3, C)$. Left ventricular

TABLE 1. Animal characteristics and events

\begin{tabular}{lccc}
\hline \multicolumn{1}{c}{ Group } & $\begin{array}{c}\text { STH-Pol-B } \\
(\mathbf{n}=\mathbf{7})\end{array}$ & $\begin{array}{c}\text { STH2-B } \\
(\mathbf{n}=\mathbf{6})\end{array}$ & $\boldsymbol{P}$ value \\
\hline BW, kg & $52 \pm 9$ & $62 \pm 11$ & .1 \\
HW, g & $225 \pm 28^{*}$ & $284 \pm 31^{*}$ & .01 \\
Heart wet/dry ratio, \% & $20.0 \pm 0.7$ & $19.3 \pm 0.8$ & .11 \\
Time to asystole, s & $154 \pm 173$ & $170 \pm 88$ & .84 \\
VF & 5 & 3 & 1.00 \\
PM $(\%)$ & $0(0)$ & $0(0)$ & 1.0 \\
\hline
\end{tabular}

Values are given as mean \pm standard deviation. $S T H-P o l-B$, New St Thomas' Hospital Polarizing blood cardioplegia; STH2-B, St Thomas' Hospital blood cardioplegia No. 2; $B W$, body weight; $H W$, heart weight; $V F$, ventricular fibrillation; $P M$, number of animals that demanded a pacemaker during reperfusion. $* P<.05$. contractility described by $\mathrm{dp} / \mathrm{dt}_{\max }$ was significantly greater in STH-Pol-B $(P=.027$; Figure $3, D)$, whereas $\mathrm{dp} / \mathrm{dt}_{\min }$ was comparable in both groups $(P=.608)$.

\section{Biochemical Data}

During reperfusion, arterial CK-MB $(P=.283)$, troponin I $(P=.543)$, and malondialdehyde $(P=.709$; Figure E3 $)$ were similar (Table 2), whereas coronary CK-MB showed a tendency to be significantly lower in STH-Pol-B-treated hearts $(P=.058$; Table 2$)$. On-pump arterial and coronary lactate levels were slightly, but not significantly, greater (arterial lactate: $P=.501$; coronary lactate: $P_{\text {interaction }}=.005$; Table 2) in the STH2-B group; coronary $\mathrm{pH}$ was correspondingly and significantly acidotic in STH2$\mathrm{B}$ at 30 minutes $(P=.03)$ and 60 minutes $(P=.01)$ of reperfusion (Table 2$)$. In addition, there was a trend $(P=.06$; Table 3) toward increased myocardial oxygen content, in STH-Pol-B, whereas myocardial oxygen consumption and myocardial oxygen extraction were similar in both groups (both n.s., data not shown).

Arterial CK-MB $(P=.283)$ as well as troponin I $(P=.534)$ were comparable in both groups (Table 3$)$. High-energy phosphates were analyzed at the end of the experiment. There was no significant difference in levels of hypoxanthine between groups (Table E3).

\section{Electron Microscopy Data}

None of the hearts in either group showed severe to irreversible damage. In STH-Pol-B, 2 samples showed no damage, 1 slight damage, 1 slight-to-moderate damage, and 3 moderate damage. In STH2-B, 1 sample showed no damage, 1 no to slight damage, 2 slight damage, and 3 samples showed slight-to-moderate damage indicating similar protection with both cardioplegic solutions $(P=.42$; Figures E4 and E5).

\section{Differential Expression of miRNAs in Left Ventricle (LV) Tissue Samples}

For next-generation sequencing, myocardial LV samples were taken at the end of the experiment to identify the miRNAs expression pattern. Overall, 238 miRNAs were detected in all samples with a minimum abundance of 1 tags per million (TPM). Expression of top-regulated miRNAs $(P<.3)$ are shown in Table E4. Principal component analysis suggested that miRNA expression in the LV was not primarily influenced by the type of cardioplegic solution. Interestingly, elevated expression of ssc-miR-122 correlated positively with troponin-I after 150 minutes of reperfusion, irrespectively of the type of cardioplegic solution applied. The TPM values of 2 miRNAs, ssc-miR-708-5p (STH-Pol-B vs STH2-B: $26 \pm 13$ vs $42 \pm 21$ TPM; $P=.019)$ and ssc-miR-122 (STH-Pol-B vs STH2-B: $25 \pm 35$ vs $10 \pm 8$ TPM; $P=.046$ ), were significantly different between STH-Pol-B and STH2-B (Figure 4, A). 
TABLE 2. Parameters during on-pump reperfusion phase

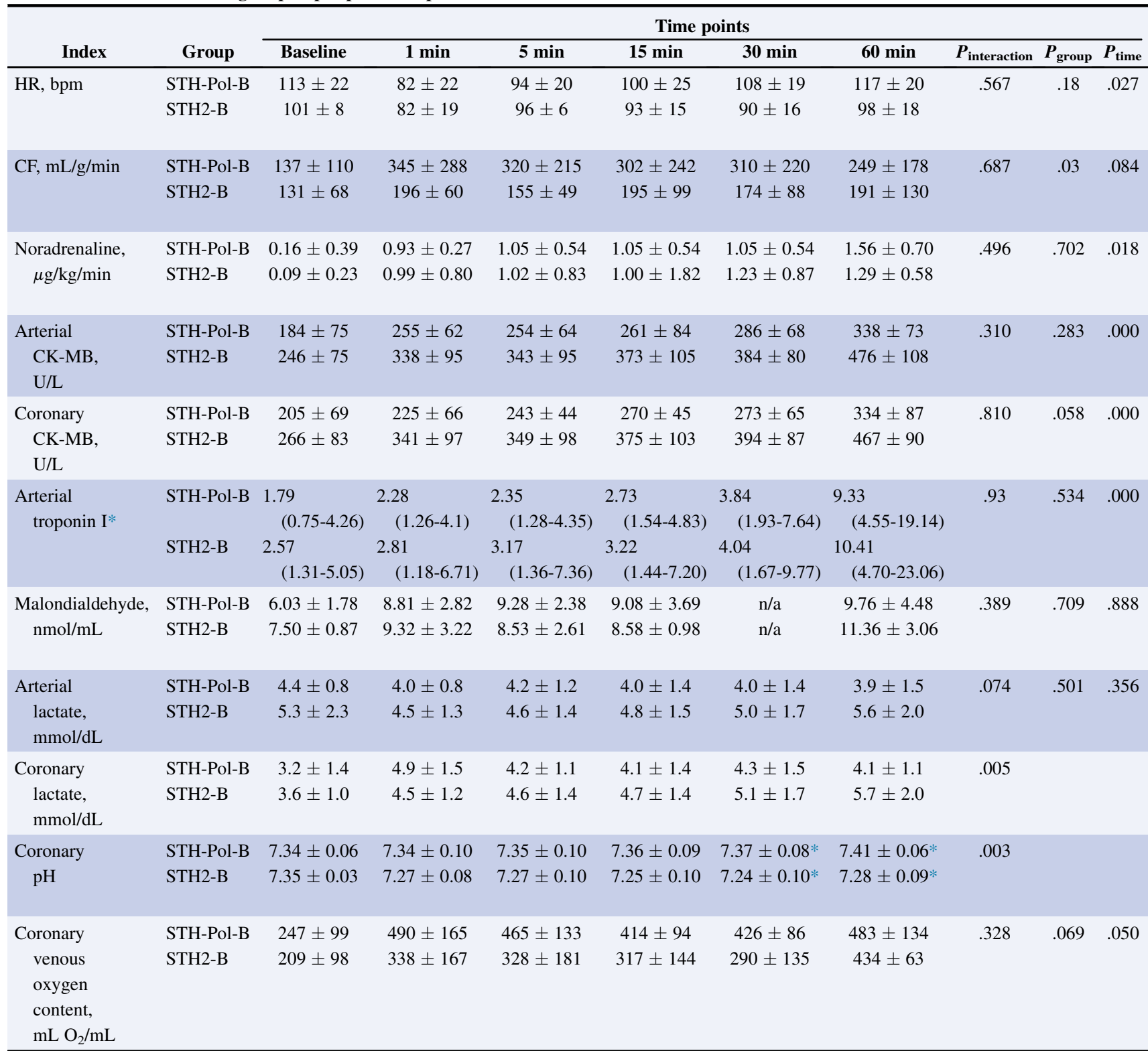

Values are mean \pm standard deviation unless noted. Groups were compared in the following biochemical parameters: arterial and coronary CK-MB, malondialdehyde, arterial and coronary lactate, as well as coronary pH. $P$ values are given for interaction $\left(P_{\text {interaction }}\right)$, between groups $\left(P_{\text {group }}\right)$, and within groups $\left(P_{\text {time }}\right)$. HR, Heart rate; STH-Pol-B, new St Thomas' Hospital Polarizing blood cardioplegia; STH2-B, St Thomas' Hospital blood cardioplegia No. 2; $C F$, coronary flow; $C K$ - $M B$, creatine kinase-muscle/brain. *Original data were right-skewed data; therefore, geometric means with $95 \%$ confidence interval are given.

Interestingly, there was a significant positive correlation between ssc-miR-122 expression and troponin I after (150 minutes of reperfusion), irrespectively of the type of cardioplegic solution applied $(P<.0001, \mathrm{r}=0.9061$; Figure $4, B)$. In addition, we performed network analysis (Mirnet) to assess the intersection between experimentally verified targets of miR-122-5p and miR-708-5p. We observed only a very small overlap in experimentally verified genes (5 genes: SRF, SLC7A5, PRSS16, YKT6, and FOXJ3; Figure $4, C$ ) between both miRNAs. In addition, subsequent analysis for the assessment of proinflammatory cytokines (tumor necrosis factor [TNF]-alpha, interleukin [IL]-6, and high mobility group box 1 [HMGB1]) and apoptosis (Caspase-3) related genes showed no differences between the groups (TNF-alpha: $P=.78$; IL-6: $P=.85$; HMGB1: $P=.84$; Caspase-3: $P=.09$; Figure E6).

\section{DISCUSSION}

This study characterized the effects of low-dose polarized STH-Pol-B during prolonged on-pump and off-pump reperfusion after 60 minutes of cardiac arrest. The data reveal similar myocardial protection with STH-Pol-B 


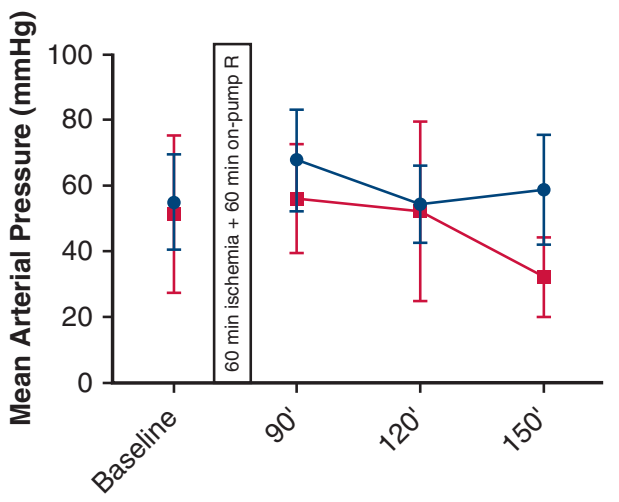

A

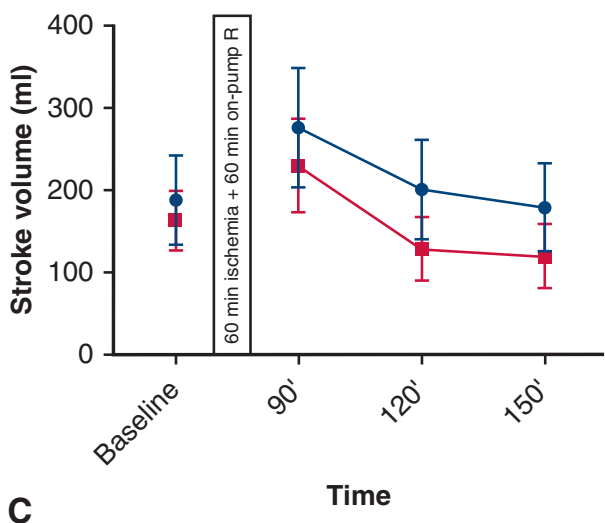

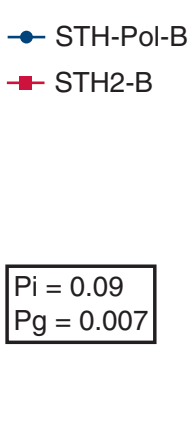

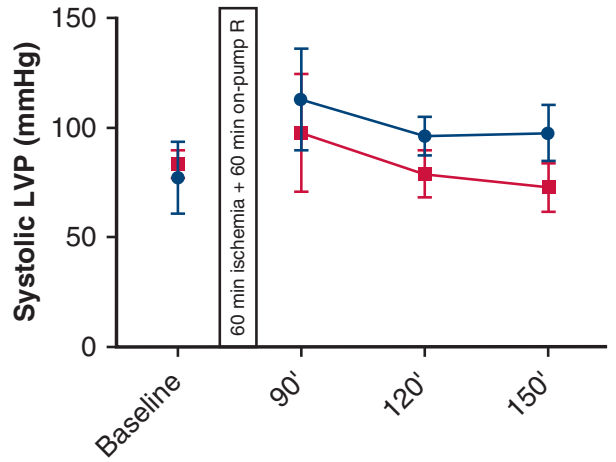

B

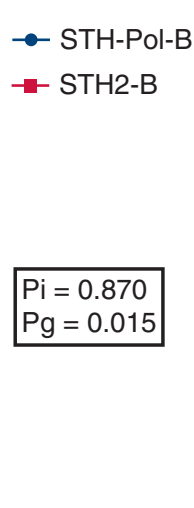

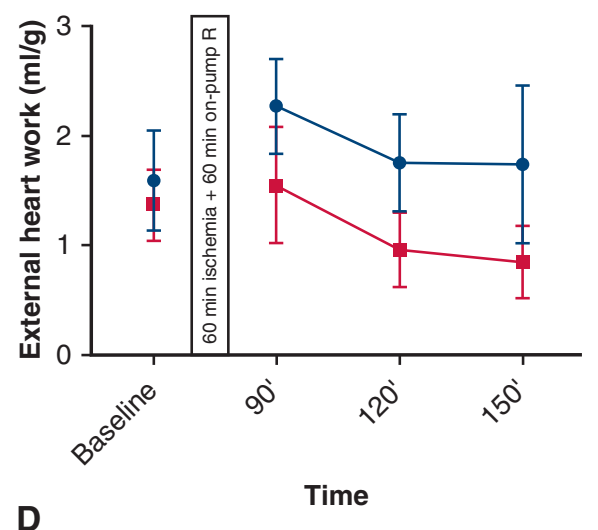

•- STH-Pol-B

$\rightarrow$ STH2-B

$\mathrm{Pi}=0.607$

$\mathrm{Pg}=0.000$

- STH-Pol-B

STH2-B

$\mathrm{Pi}=0.889$

$\mathrm{Pg}=0.012$

FIGURE 2. Hemodynamic data were recorded at baseline and every 30 minutes during off-pump reperfusion. Mean arterial pressure (A), systolic left ventricular pressure (LVP; B), stroke volume (C), and external heart work (D) were significantly increased in STH-Pol-B. Values are mean \pm standard deviation; $P$ values are given for interaction $(P i)$ and between groups $(P g)$. STH-Pol-B, New St Thomas' Hospital Polarizing blood cardioplegia; STH2-B, St Thomas' Hospital blood cardioplegia No. 2.

compared with STH2-B. During 60 minutes of on-pump reperfusion, arterial and coronary CK-MB were comparable. Notably, hemodynamics were significantly improved after weaning from $\mathrm{CPB}$ : diastolic $\mathrm{AP}$, mean arterial pressure, systolic LVP, left ventricular end-systolic pressure, CO, stroke volume, EHW, and dp/dt ${ }_{\max }$ (indicating better systolic function) were significantly greater in STH-Pol-B. Wedge pressure was decreased after weaning, indicating improved diastolic function. In addition, the present study for the first time describes the pattern of miRNAs in pig's myocardium following CPB. The data supports noninferiority of polarized arrest with STH-Pol-B compared with conventional depolarized arrest with STH2-B in a porcine model.

Beta blockers in general ${ }^{10}$ and esmolol in particular have already been used clinically as continuous coronary perfusion during cardiac surgery. ${ }^{11}$ Esmolol has a short halflife (approximately 9 minutes) and is hydrolyzed by red blood cell esterases, ${ }^{12}$ which rapidly reverse negative inotropic effects during reperfusion. We showed comparable echocardiographic measurements at baseline and at the end of the experiments, next to hemodynamic improvements in STH-Pol-B. Esmolol did clearly not dampen hemodynamics since parameters such as HR, systolic AP, and LVP were significantly improved in STH-Pol-B. Stable hemodynamic conditions during on-pump reperfusion and after weaning are important requirements in fragile hearts during cardiac surgery.

Adenosine prevents $\mathrm{Ca}^{2+}$ overload and is cardioprotective during hyperkalemia-induced cardioplegic arrest by lessening the risk for ventricular dysfunction. ${ }^{13}$ Besides the beneficial hemodynamic effects, STH-Pol-B maintained normal $\mathrm{pH}$ values in the coronary blood whereas in STH2-B hearts, acidic $\mathrm{pH}$ values were observed during reperfusion. By inhibition of mitochondrial permeability transition formation ${ }^{14}$ moderate acidosis during ischemia is cardioprotective; however, the following normalization of $\mathrm{pH}$ during reperfusion induces the opening of mitochondrial permeability transition and leads to apoptosis. ${ }^{14}$ Changes in $\mathrm{pH}$ should be avoided during ischemia-reperfusion. 


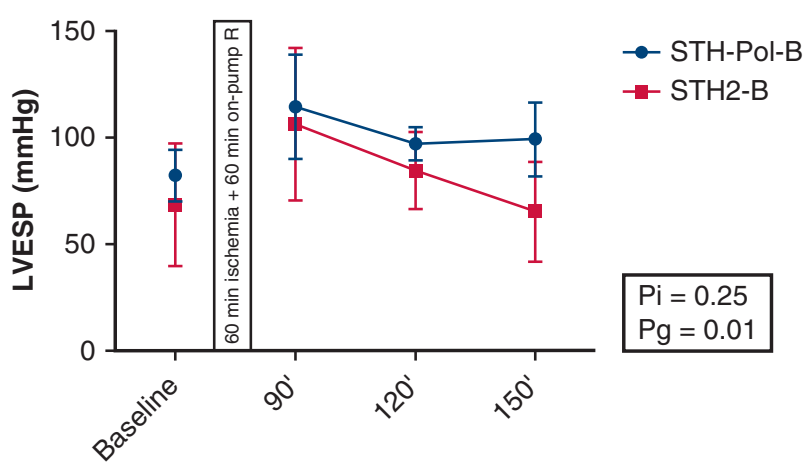

A

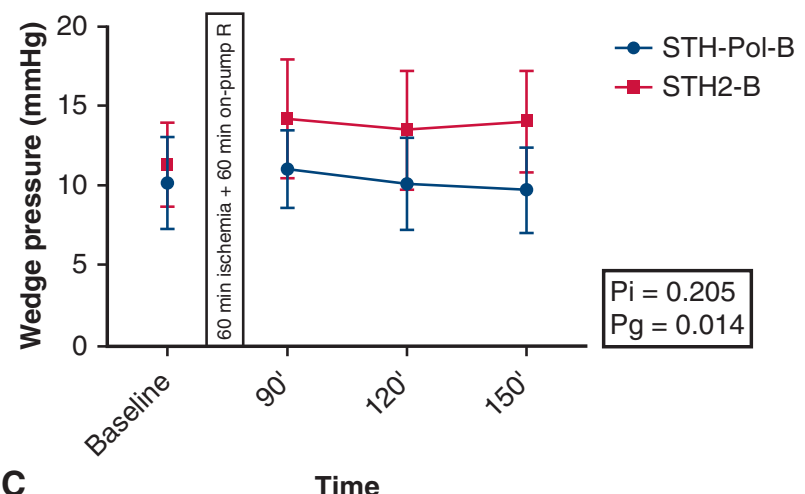

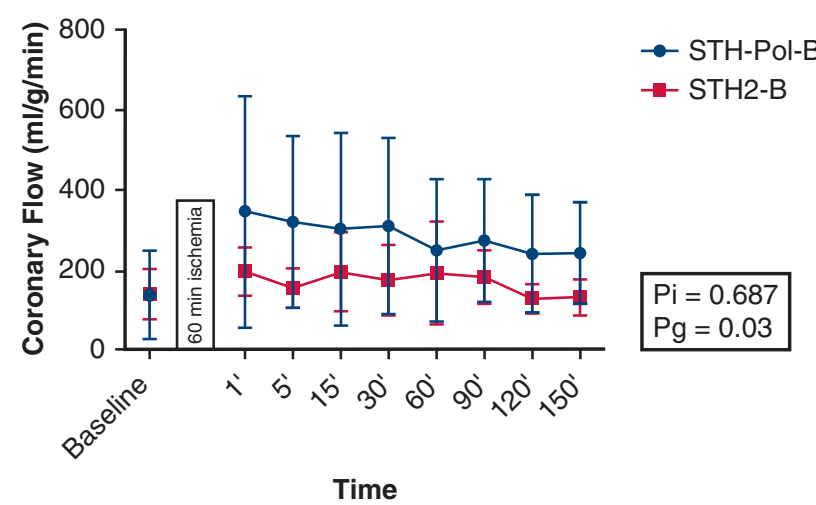

B

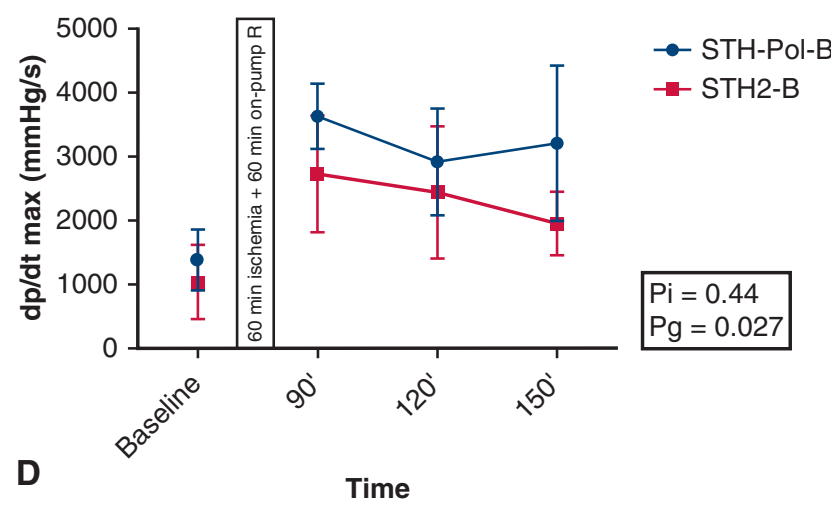

FIGURE 3. Hemodynamic data were recorded at baseline and every 30 minutes during off-pump reperfusion. Left ventricular end systolic pressure (LVESP; A) as well as coronary flow (B) were significantly elevated, wedge pressure (C) was significantly alleviated and $\mathrm{dp} / \mathrm{dt}_{\max }(\mathrm{D})$ was significantly improved in STH-Pol-B. Values are mean $\pm \mathrm{SD} ; P$ values are given for interaction $(P i)$ and between groups $(P g)$. STH-Pol-B, New St Thomas' Hospital Polarizing blood cardioplegia; STH2-B, St Thomas' Hospital blood cardioplegia No. 2.

Therefore, our preserved coronary blood $\mathrm{pH}$ values underline the biochemical advantages of polarized arrest.

Recently, Aass and colleagues ${ }^{7}$ performed a comparable study about the effect of polarized cardioplegia on energy metabolism and cardiac function. They showed an improved cardiac index after 150 minutes of reperfusion. The most important findings were increased levels of phosphocreatine and ATP during late ischemia and early phase of reperfusion in hearts preserved with STH-Pol-B. After 180 minutes of reperfusion, these differences were no longer detectable. The major difference as compared with the present study was the temperature of cardioplegia during application $\left(4^{\circ} \mathrm{C}\right.$ vs $\left.12^{\circ} \mathrm{C}\right)$ and the time of on-pump reperfusion (60 minutes vs 10 minutes). This longer reperfusion period of 60 minutes was chosen since it is known that controlled reperfusion is beneficial in hearts with reduced function, ${ }^{15}$ which is—next to old age-a predictor for increased inotropic support after weaning from CPB. ${ }^{16}$ The main reason for using a lower temperature was based on previous studies that demonstrated the efficacy and cardioprotective effect of administration at low temperature. ${ }^{17}$ These differences might explain the enhanced cardiac function and reduction in myocardial damage in comparison with the work of Aass and coworkers. $^{7}$

In addition, we investigated expression levels of miRNAs in LV tissue samples. Previously, only a few studies have investigated the expression pattern of miRNAs in the setting of CPB. However, these previous studies investigated the expression of miRNAs in CPB using microarray analysis with a preselected number of miRNAs. To the best of our knowledge, no study so far identified miRNAs in myocardial LV tissue samples obtained from hearts subjected to cardioplegia and reperfusion. With next-generation sequencing, overall 238 miRNAs were identified to be robustly expressed in LV tissue; only 2 miRNAs (miR708-5p and miR-122) showed statistically different expression levels between the 2 groups. A recent pioneering study identified miR-708 as an anti-inflammatory miRNA in endothelial and vascular smooth muscle cells, and there is 
TABLE 3. Hemodynamics after weaning from CPB

\begin{tabular}{|c|c|c|c|c|c|c|c|c|}
\hline \multirow{2}{*}{ Index } & \multirow[b]{2}{*}{ Group } & \multicolumn{7}{|c|}{ Time points } \\
\hline & & Baseline & 90 min & 120 min & 150 min & $P_{\text {interaction }}$ & $P_{\text {group }}$ & $\overline{P_{\text {time }}}$ \\
\hline \multirow[t]{2}{*}{ HR, bpm } & STH-Pol-B & $113 \pm 22$ & $117 \pm 24$ & $109 \pm 9$ & $113 \pm 10$ & .567 & .18 & .027 \\
\hline & STH2-B & $101 \pm 8$ & $99 \pm 6$ & $108 \pm 28$ & $104 \pm 16$ & & & \\
\hline \multirow{2}{*}{$\begin{array}{l}\text { Systolic AP, } \\
\text { mm Hg }\end{array}$} & STH-Pol-B & $72 \pm 16$ & $115 \pm 24$ & $113 \pm 24$ & $113 \pm 33$ & .541 & .127 & .424 \\
\hline & STH2-B & $77 \pm 13$ & $93 \pm 26$ & $89 \pm 32$ & $68 \pm 37$ & & & \\
\hline \multirow{2}{*}{$\begin{array}{l}\text { Diastolic AP } \\
\text { mm Hg }\end{array}$} & STH-Pol-B & $42 \pm 11$ & $47 \pm 9$ & $37 \pm 10$ & $37 \pm 8$ & .092 & .032 & .03 \\
\hline & STH2-B & $46 \pm 10$ & $39 \pm 9$ & $39 \pm 18$ & $24 \pm 9$ & & & \\
\hline \multirow[t]{2}{*}{ MAP, mm Hg } & STH-Pol-B & $55 \pm 15$ & $68 \pm 16$ & $54 \pm 12$ & $59 \pm 17$ & .09 & .007 & .003 \\
\hline & STH2-B & $60 \pm 9$ & $56 \pm 17$ & $52 \pm 27$ & $32 \pm 12$ & & & \\
\hline \multirow{2}{*}{$\begin{array}{l}\text { RAP, mean, } \\
\text { mm Hg }\end{array}$} & STH-Pol-B & $6 \pm 5$ & $8 \pm 5$ & $7 \pm 4$ & $7 \pm 4$ & .149 & .296 & .291 \\
\hline & STH2-B & $8 \pm 2$ & $9 \pm 2$ & $8 \pm 3$ & $10 \pm 6$ & & & \\
\hline \multirow{2}{*}{$\begin{array}{l}\text { Systolic LVP, } \\
\text { mm Hg }\end{array}$} & STH-Pol-B & $77 \pm 16$ & $113 \pm 23$ & $96 \pm 9$ & $97 \pm 13$ & .607 & .000 & .083 \\
\hline & STH2-B & $83 \pm 6$ & $98 \pm 27$ & $79 \pm 11$ & $73 \pm 11$ & & & \\
\hline \multirow[t]{2}{*}{$\mathrm{SV}, \mathrm{mL} / \mathrm{g} /$ beat } & STH-Pol-B & $189 \pm 54$ & $274 \pm 79$ & $201 \pm 60$ & $180 \pm 54$ & .870 & .015 & .001 \\
\hline & STH2-B & $165 \pm 31$ & $245 \pm 60$ & $129 \pm 39$ & $136 \pm 30$ & & & \\
\hline \multirow[t]{2}{*}{$\mathrm{CO}, \mathrm{mL} / \mathrm{g} \mathrm{hw}$} & STH-Pol-B & $20 \pm 3$ & $20 \pm 3$ & $18 \pm 4$ & $17 \pm 5$ & .347 & .282 & .005 \\
\hline & STH2-B & $17 \pm 3$ & $17 \pm 4$ & $13 \pm 3$ & $15 \pm 2$ & & & \\
\hline \multirow[t]{2}{*}{ EHW, mL/g hw } & STH-Pol-B & $1.60 \pm 0.46$ & $2.28 \pm 0.43$ & $1.76 \pm 0.45$ & $1.75 \pm 0.72$ & .889 & .012 & .044 \\
\hline & STH2-B & $1.38 \pm 0.28$ & $1.56 \pm 0.53$ & $0.97 \pm 0.34$ & $0.98 \pm 0.28$ & & & \\
\hline \multirow[t]{2}{*}{ LVESP, mm Hg } & STH-Pol-B & $82 \pm 12$ & $114 \pm 25$ & $97 \pm 8$ & $99 \pm 18$ & .25 & .01 & .066 \\
\hline & STH2-B & $79 \pm 13$ & $106 \pm 36$ & $84 \pm 18$ & $65 \pm 23$ & & & \\
\hline \multirow[t]{2}{*}{ LVEDP, mm Hg* } & STH-Pol-B & $12.38(10.09-15.19)$ & $17.72(11.88-26.42)$ & $14.83(11.65-18.86)$ & $13.12(10.54-16.33)$ & .073 & .411 & .474 \\
\hline & STH2-B & $9.44(2.97-29.96)$ & $14.67(13.13-16.4)$ & $14.74(13.06-16.63)$ & $17.29(11.67-25.61)$ & & & \\
\hline \multirow[t]{2}{*}{$\mathrm{CF}, \mathrm{mL} / \mathrm{g} / \mathrm{min}$} & STH-Pol-B & $137 \pm 110$ & $264 \pm 167$ & $241 \pm 147$ & $242 \pm 127$ & .687 & .03 & .084 \\
\hline & STH2-B & $131 \pm 68$ & $181 \pm 68$ & $128 \pm 36$ & $132 \pm 44$ & & & \\
\hline \multirow[t]{2}{*}{ Wedge, $\mathrm{mm} \mathrm{Hg}$} & STH-Pol-B & $10 \pm 3$ & $11 \pm 2$ & $10 \pm 3$ & $10 \pm 3$ & .205 & .014 & .573 \\
\hline & STH2-B & $11 \pm 3$ & $14 \pm 4$ & $14 \pm 4$ & $14 \pm 3$ & & & \\
\hline \multirow{2}{*}{$\mathrm{dp} / \mathrm{dt}_{\max }, \mathrm{mm} \mathrm{Hg} / \mathrm{s}$} & STH-Pol-B & $1387 \pm 474$ & $3632 \pm 508$ & $2914 \pm 834$ & $3206 \pm 1226$ & .44 & .027 & .114 \\
\hline & STH2-B & $1038 \pm 583$ & $2726 \pm 918$ & $2437 \pm 1032$ & $1957 \pm 495$ & & & \\
\hline \multirow[t]{2}{*}{ Arterial CK-MB, U/L } & STH-Pol-B & $184 \pm 75$ & $472 \pm 116$ & $482 \pm 141$ & $494 \pm 151$ & .310 & .283 & .000 \\
\hline & STH2-B & $246 \pm 75$ & $526 \pm 91$ & $516 \pm 111$ & $494 \pm 111$ & & & \\
\hline \multirow[t]{2}{*}{ Arterial troponin-I* } & STH-Pol-B & $1.79(0.75-4.26)$ & $31.64(15.66-63.95)$ & $44.73(20-100.1)$ & $50.21(16.38-153.9)$ & .93 & .534 & .000 \\
\hline & STH2-B & $2.57(1.31-5.05)$ & $22.65(11.22-45.74)$ & $34.18(20.58-56.79)$ & $45.3(34.14-60.1)$ & & & \\
\hline
\end{tabular}


TABLE 3. Continued

\begin{tabular}{|c|c|c|c|c|c|c|c|c|}
\hline \multirow[b]{2}{*}{ Index } & \multirow[b]{2}{*}{ Group } & \multicolumn{7}{|c|}{ Time points } \\
\hline & & Baseline & $90 \mathrm{~min}$ & 120 min & $150 \mathrm{~min}$ & $P_{\text {interaction }}$ & $P_{\text {group }}$ & $P_{\text {time }}$ \\
\hline \multirow{2}{*}{$\begin{array}{l}\text { Arterial lactate, } \\
\mathrm{mmol} / \mathrm{dL}\end{array}$} & STH-Pol-B & $4.4 \pm 0.8$ & $3.9 \pm 1.5$ & $4.4 \pm 2.5$ & $4.8 \pm 3.5$ & .074 & .501 & .356 \\
\hline & STH2-B & $5.3 \pm 2.3$ & $6.1 \pm 1.6$ & $7.1 \pm 2.6$ & $9.1 \pm 2.9$ & & & \\
\hline \multirow{2}{*}{$\begin{array}{c}\text { Noradrenaline, } \\
\mu \mathrm{g} / \mathrm{kg} / \mathrm{min}\end{array}$} & STH-Pol-B & $0.16 \pm 0.39$ & $1.70 \pm 1.08$ & $1.66 \pm 1.01$ & $1.99 \pm 1.11$ & .496 & .792 & .018 \\
\hline & STH2-B & $0.09 \pm 0.23$ & $1.29 \pm 0.58$ & $1.81 \pm 0.62$ & $1.94 \pm 1.28$ & & & \\
\hline
\end{tabular}

After weaning from CPB, the following parameters were recorded: HR, CF, systolic and diastolic AP, MAP, RAP, LVP, SV, CO, EHW, LVESP and LVEDP, wedge pressure, dp/ $\mathrm{dt}_{\max }, \mathrm{CF}$, and noradrenaline administration. Furthermore, groups were compared in the following biochemical parameters: arterial CK-MB and arterial lactate. Values are mean \pm standard deviation unless noted. $P$ values are given for interaction $\left(P_{\text {interaction }}\right)$, between groups $\left(P_{\text {group }}\right)$, and within groups $\left(P_{\text {time }}\right)$. $H R$, Heart rate; $S T H-P o l-B$, new St Thomas' Hospital Polarizing blood cardioplegia; $S T H 2-B$, St Thomas' Hospital blood cardioplegia No. 2; AP, systolic and diastolic arterial pressure; $M A P$, mean arterial pressure; $R A P$, right atrial pressure; $L V P$, systolic left ventricular pressure; $S V$, stroke volume; $C O$, cardiac output; $E H W$, external heart work; $L V E S P$, left ventricular end-systolic pressure; $L V E D P$, left ventricular end-diastolic pressure wedge pressure; $C F$, coronary flow; $C K$ - $M B$, creatine kinase-muscle/brain. $*$ Original data were right-skewed data; therefore, geometric means with $95 \%$ confidence interval are given.

substantial evidence that inflammation contributes to impaired cardiac and vascular function during $\mathrm{CPB}{ }^{18}$ Therefore, we performed subsequent analysis for the assessment of proinflammatory cytokines (TNF-alpha, IL-6, and HMGB1) and apoptosis (Caspase-3) related genes. There were no differences between the groups (Figure E6). In addition, upregulation of miR-708 expression following ischemia-reperfusion may have deleterious effects on cardiac contractility and intracellular $\mathrm{Ca}^{2+}$ homeostasis by acting on cardiac neuronal nitric oxide synthase. ${ }^{19}$ In line
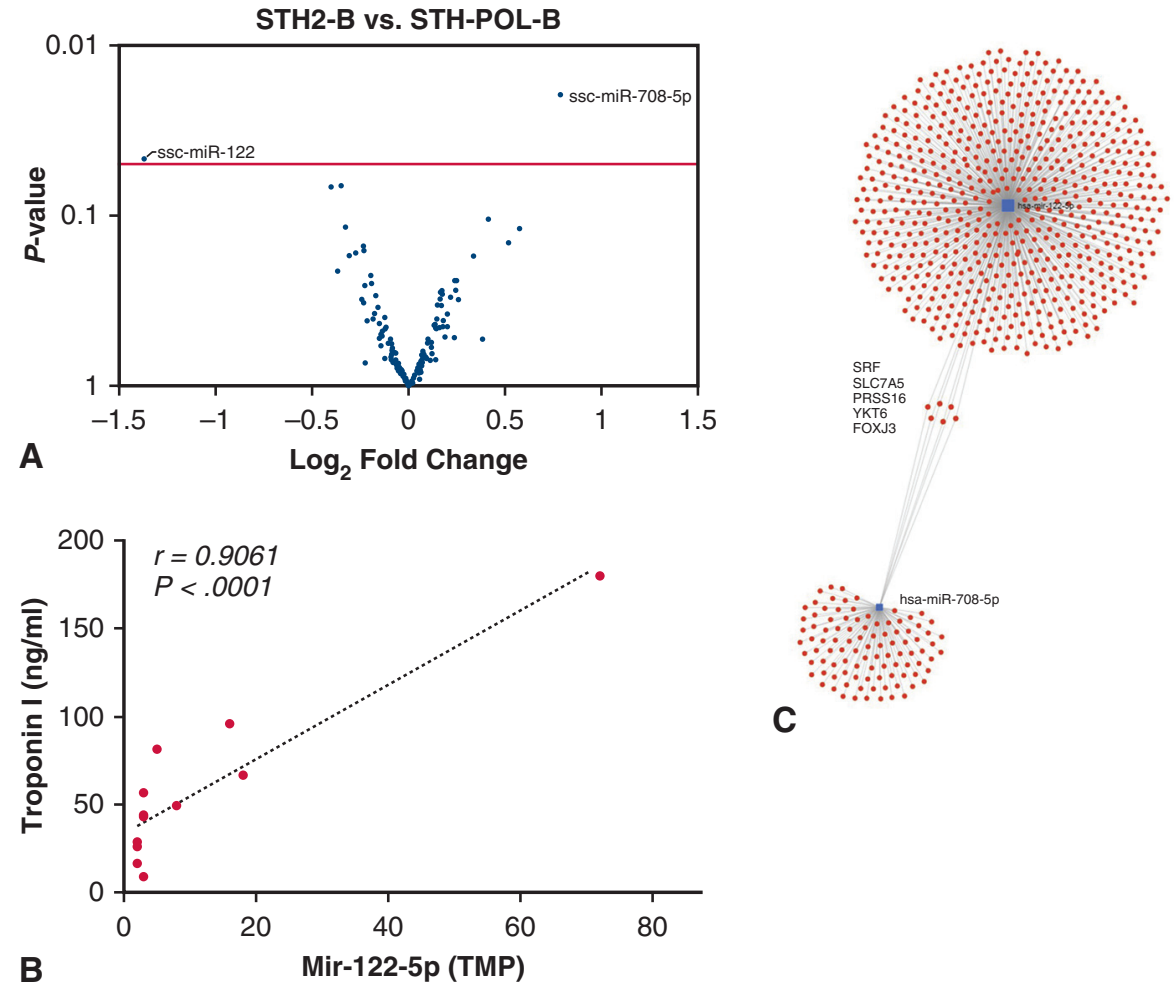

FIGURE 4. Distinct myocardial microRNA expression profiles of STH2-B group compared with the STH-Pol-B group. A, Volcano plot of the miRNA expression levels in STH2-B and STH-Pol-B group in the discover set. The horizontal line represents a $P$ value of .05 and miR-122-5p and miR-708-5p plots (red) represent the differentially expressed miRNAs with statistical significance. B, miR-122 expression in the left ventricle samples correlates with peripheral troponin I levels, independent of the cardioplegic solution (each plot represents an individual pig). C, miRNA (mir-122 and mir-708)mRNA network analysis and intersection between experimentally verified target genes (SRF, SLC7A5, PRSS16, YKT6, FOXJ3) of miR-122-5p and miR-708-5p overlapping. STH-Pol-B, New St Thomas' Hospital Polarizing blood cardioplegia; STH2-B, St Thomas' Hospital blood cardioplegia No. 2. 
with this, downregulation of mir-708 expression in STHPol-B group might contribute to improve LV systolic function. MiR-122 has been shown that its levels positively correlate to cardiac troponin-I following acute myocardial infarction and progression of heart failure. ${ }^{20}$ Accordingly, we found that miR-122 expression in the LV samples correlates with peripheral troponin-I levels, independent of the cardioplegic solution. This result indicates that miR-122 might be a potential biomarker of ischemia-reperfusion injury following CPB.

Previous clinical studies showed clinical efficacy of polarized arrest (microplegia: lidocaine, magnesium, and adenosine) with improved hemodynamics and reduced reperfusion damage in patients with unstable angina. ${ }^{21}$ It is of interest that the principal component of the described "polarizing" solution is lidocaine, a Na-channel blocker with a considerable half-life of 90 to 120 minutes with normally functioning liver and kidney. In contrast, the half-life of esmolol is about 9 minutes. We think that this makes esmolol (which acts to inhibit both the $\mathrm{Ca}$-channel and the $\mathrm{Na}-$ channel) a safer drug to use in the acute setting of cardiac surgery, as it is extremely unlikely that there will be any residual drug remaining in the systemic circulation at the end of $\mathrm{CPB}$, in contrast to the highly likely scenario that lidocaine at relatively high concentrations may remain systemically. Furthermore, STH-Pol-B is not comparable with reduced volume solutions; in fact, this form of application might not be sufficient for every patient. ${ }^{22}$

The present study has the following limitations. Experiments were performed on healthy pigs with an ischemia time of 60 minutes to provide comparable experimental conditions with our collaborators in Norway. ${ }^{7}$ Animals

\section{Polarizing St Thomas' Hospital blood cardioplegia}
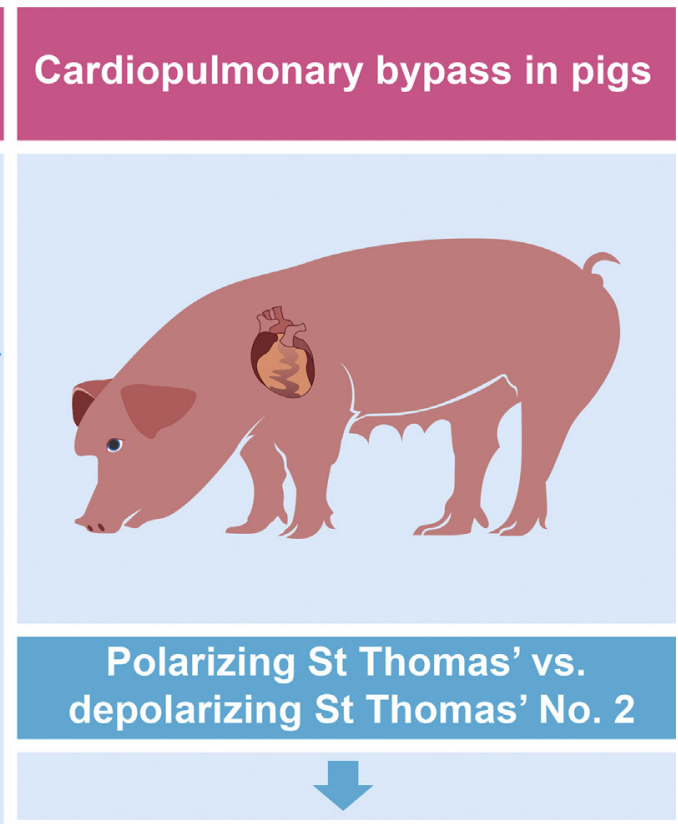

\section{Advantage of polarized arrest}
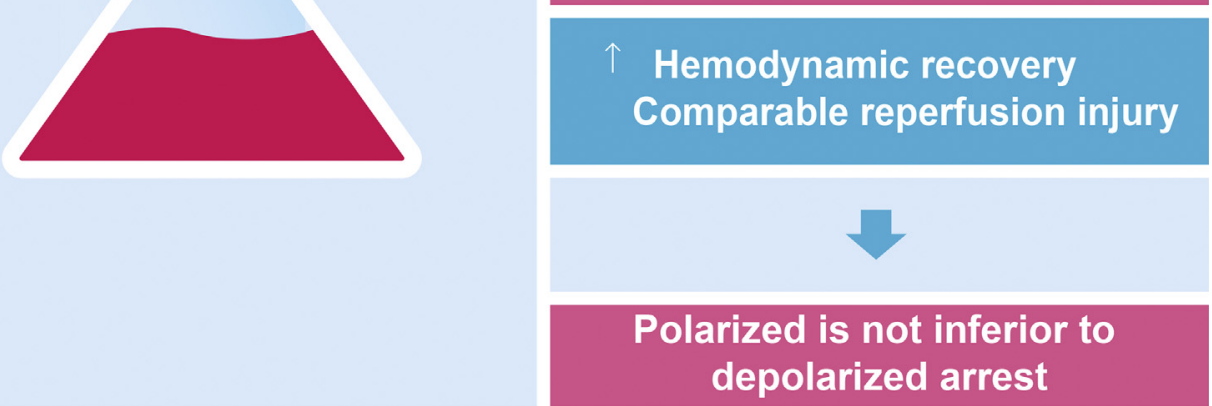

FIGURE 5. The new St Thomas' Polarized Hospital blood cardioplegia consists of 3 main components (esmolol, magnesium, and adenosine) and was compared with depolarized St Thomas' No. 2 blood cardioplegia in a cardiopulmonary bypass model in pigs. Results showed improved hemodynamic recovery and similar reperfusion injury, which supports noninferiority of polarized arrest. 


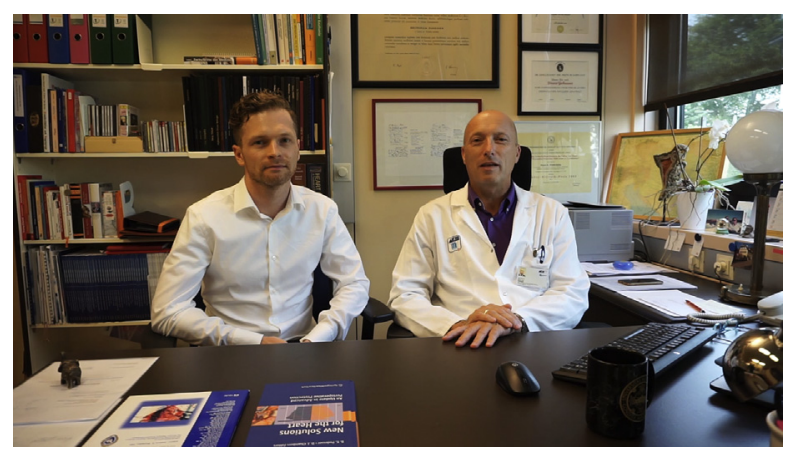

VIDEO 1. Bruno K. Podesser, senior author, and David Santer, first author, provide a brief introduction on the hypothesis, design, and results of the study. Video available at: https://www.jtcvs.org/article/S00225223(18)33254-9/fulltext.

underwent on-pump reperfusion of 60 minutes to guarantee controlled reperfusion under comparable flow rates, pressures, and hemoglobin. Under these standardized conditions, analysis of cardiac enzymes from coronary sinus blood was performed. Besides CK-MB, we also analyzed the more sensitive parameter troponin I, which also showed comparable results in both groups. It is important to mention that we were aware that esmolol is hydrolyzed by red blood cell esterases. Therefore, the crystalloid components of the cardioplegia were placed on ice and mixed with the ice-cold blood of the pig just before administration. Although a sample size was defined, it is possible that between-group differences might be caused by a sampling error due to the low number of pigs. In addition, this study does not provide pressure-volume relationships, since measurements were performed with a pressure-tip catheter. Since correction for multiple testing has not been performed, the miRNA findings in this study are of exploratory nature and require further replication to verify their relevance for the regulation of gene activity in hearts undergoing cardioplegic arrest.

In summary, the functional, biochemical and molecular data of this study suggests the noninferiority as well as potential benefits of a novel hypothermic blood-based polarized St Thomas' Hospital cardioplegic solution in a clinically relevant model of CPB in pigs (Figure 5 and Video 1).

\section{Conflict of Interest Statement}

Matthias Hackl is co-founder of TAmiRNA. David J. Chambers is co-inventor of the STH-Pol solution. All other authors have nothing to disclose with regard to commercial support.

We thank the cardiotechnicians of the Department of Cardiac Surgery, Universitaetsklinikum St Poelten, Austria—Susanna Skalicky, BSc (TamiRNA) for support, Gerd Kager for high-energy phosphates measurements (Medical University Graz, Austria), and Alexander Weigl, MPharm, AKH Linz, Austria, for providing St Thomas' cardioplegia.

\section{References}

1. Podesser BK, Chambers DJ. New Solutions for the Heart: An Update in Advanced Perioperative Protection. Wien, New York: Springer; 2011.

2. Schmidtler FW, Tischler I, Lieber M, Weingartner J, Angelis I, Wenke K, et al Cardiac surgery for octogenarians - a suitable procedure? Twelve-year operative and post-hospital mortality in 641 patients over 80 years of age. Thorac Cardiovasc Surg. 2008;56:14-9.

3. Robinson LA, Schwarz GD, Goddard DB, Fleming WH, Galbraith TA. Myocardial protection for acquired heart disease surgery: results of a national survey. Ann Thorac Surg. 1995;59:361-72.

4. Chambers DJ, Fallouh HB. Cardioplegia and cardiac surgery: pharmacological arrest and cardioprotection during global ischemia and reperfusion. Pharmacol Ther. 2010;127:41-52.

5. Bessho R, Chambers DJ. Myocardial protection: the efficacy of an ultra-shortacting beta-blocker, esmolol, as a cardioplegic agent. J Thorac Cardiovasc Surg. 2001;122:993-1003.

6. Fallouh HB, Bardswell SC, McLatchie LM, Shattock MJ, Chambers DJ, Kentish JC. Esmolol cardioplegia: the cellular mechanism of diastolic arrest. Cardiovasc Res. 2010;87:552-60.

7. Aass T, Stangeland L, Chambers DJ, Hallström S, Rossmann C, Podesser BK, et al. Myocardial energy metabolism and ultrastructure with polarizing and depolarizing cardioplegia in a porcine modeldagger. Eur J Cardiothorac Surg. 2017; 52:180-8.

8. Fujii M, Chambers DJ. Cardioprotection with esmolol cardioplegia: efficacy as a blood-based solution. Eur J Cardiothorac Surg. 2013;43:619-27.

9. Robinson MD, McCarthy DJ, Smyth GK. edgeR: a Bioconductor package for differential expression analysis of digital gene expression data. Bioinformatics. 2010;26:139-40.

10. Podesser BK, Schwarzacher S, Zwoelfer W, Binder TM, Wolner E, Seitelberger R. Comparison of perioperative myocardial protection with nifedipine versus nifedipine and metoprolol in patients undergoing elective coronary artery bypass grafting. J Thorac Cardiovasc Surg. 1995;110:1461-9.

11. Borowski A, Korb H. Myocardial protection by pressure- and volume-controlled continuous hypothermic coronary perfusion (PVC-CONTHY-CAP) in combination with ultra-short beta-blockade and nitroglycerine. Thorac Cardiovasc Surg. 1997;45:51-4

12. Erhardt PW, Woo CM, Matier WL, Gorczynski RJ, Anderson WG. Ultra-shortacting beta-adrenergic receptor blocking agents. 3. Ethylenediamine derivatives of (aryloxy)propanolamines having esters on the aryl function. J Med Chem. 1983;26:1109-12.

13. Vinten-Johansen J, Nakanishi K, Zhao ZQ, McGee DS, Tan P. Acadesine im proves surgical myocardial protection with blood cardioplegia in ischemically injured canine hearts. Circulation. 1993;88:II350-8.

14. Pell VR, Chouchani ET, Murphy MP, Brookes PS, Krieg T. Moving forwards by blocking back-flow: the Yin and Yang of MI therapy. Circ Res. 2016;118: 898-906.

15. Peterss S, Guenther S, Kellermann K, Jungwirth B, Lichtinghagen R, Haverich A, et al. An experimental model of myocardial infarction and controlled reperfusion using a miniaturized cardiopulmonary bypass in rats. Interact Cardiovasc Thorac Surg. 2014;19:561-6.

16. Royster RL, Butterworth JF IV, Prough DS, Johnston WE, Thomas JL, Hogan PE, et al. Preoperative and intraoperative predictors of inotropic support and long-term outcome in patients having coronary artery bypass grafting. Anesth Analg. 1991;72:729-36.

17. Baretti R, Mizuno A, Buckberg GD, Young HH, Baumann-Baretti B, Hetzer R Continuous antegrade blood cardioplegia: cold vs. tepid. Thorac Cardiovasc Surg. 2002;50:25-30

18. Franke A, Lante W, Fackeldey V, Becker HP, Kurig E, Zöller LG, et al. Pro-inflammatory cytokines after different kinds of cardio-thoracic surgical procedures: is what we see what we know? Eur J Cardiothorac Surg. 2005;28:569-75.

19. Strasen J, Ritter O. Role of nNOS in cardiac ischemia-reperfusion injury. Trends Cardiovasc Med. 2011;21:58-63.

20. Marques FZ, Vizi D, Khammy O, Mariani JA, Kaye DM. The transcardiac gradient of cardio-microRNAs in the failing heart. Eur J Heart Fail. 2016;18: 1000-8. 
21. Onorati F, Santini F, Dandale R, Ucci G, Pechlivanidis K, Menon T, et al. "Polarizing" microplegia improves cardiac cycle efficiency after CABG for unstable angina. Int J Cardiol. 2013;167:2739-46.

22. Gong B, Ji B, Sun Y, Wang G, Liu J, Zheng Z. Is microplegia really superior to standard blood cardioplegia? The results from a meta-analysis. Perfusion. 2015; 30:375-82.
Key Words: cardioplegia, St Thomas' Hospital No. 2, polarizing cardioplegia, animal study, micro RNA, ischemia-reperfusion, cardiopulmonary bypass, blood cardioplegia, cardioprotection 


\section{APPENDIX E1. SUPPLEMENTAL METHODS Protocol}

For premedication, ketamine $(15 \mathrm{mg} / \mathrm{kg}$ intramuscularly), acepromazine $(1.3 \mathrm{mg} / \mathrm{kg})$, and atropine $(0.5 \mathrm{mg})$ were used. Animals were anesthetized $(2.5 \mathrm{mg} / \mathrm{kg}$ propofol, $15 \mathrm{mg}$ piritramide, and $20 \mathrm{mg}$ rocuronium bromide), intubated, and ventilated. Anesthesia was maintained with piritramide $(1.875 \mathrm{mg} / \mathrm{kg} / \mathrm{h})$, rocuronium bromide $(3.7 \mathrm{mg} / \mathrm{kg} / \mathrm{h})$, and propofol $(10 \mathrm{mg} / \mathrm{kg} / \mathrm{h})$. Pressure monitoring was performed via the left femoral artery, and a central venous catheter was placed into the left external jugular vein for venous access. After sternotomy, pigs were heparinized (300 IU $/ \mathrm{kg})$, the ascending aorta (Optisite arterial cannula; Edwards Lifesciences Corp, Irvine, Calif) and the right atrium (Trim Flex venous cannula; Edwards Lifesciences Corp) were cannulated, and the pigs were put on normothermic cardiopulmonary bypass (Stockert SIII Heart Lung System; PERFUSION. COM, Inc, Fort Myers, FL). Additional monitoring included a Swan-Ganz oximetry thermodilution catheter (741HF75P; Edwards Lifesciences Corp) for pulmonary capillary wedge pressure and cardiac output, ultrasound flow probe for coronary flow of the left anterior descending coronary artery (LAD), a pressure tip catheter for left ventricular pressure (Millar Instruments, Houston, Tex), and a coronary sinus catheter to sample coronary effluent during first 60 minutes of ischemia and reperfusion.

\section{High-Energy Phosphates: Energy Status}

Samples from the mid-anterior wall of the left ventricle next to the LAD were snap frozen with precooled tongs (liquid nitrogen) and the biopsies stored in liquid nitrogen before high-energy phosphates analysis. The sample preparation and high-performance liquid chromatography (HPLC) measurement of adenosine triphosphate (ATP), adenosine diphosphate (ADP), adenosine monophosphate, and phosphocreatine, as well as hypoxanthine and xanthine were performed as previously described. ${ }^{\mathrm{E} 1, \mathrm{E} 2}$ A piece of frozen tissue (50-100 $\mathrm{mg}$ ) was homogenized with a micro-dismembranator (Braun, Melsungen, Germany) and deproteinized with $400 \mu \mathrm{L}$ of $0.4 \mathrm{~mol} / \mathrm{L}$ perchloric acid. After centrifugation $(12,000 \mathrm{~g}) 200 \mu \mathrm{L}$ of the acid extract was neutralized with 20 to $25 \mu \mathrm{L}$ of $2 \mathrm{~mol} / \mathrm{L}$ potassium carbonate $\left(4^{\circ} \mathrm{C}\right)$. The supernatant $(20 \mu \mathrm{L}$ injection volume) obtained after centrifugation was used for HPLC analysis.

To summarize in brief, separation was performed on a Hypersil ODS column $(5 \mu \mathrm{m}, 250 \mathrm{~mm} \times 4 \mathrm{~mm}$ inner diameter) using a L-2200 autosampler, 2 L-2130 HTA pumps, and an L-2450 diode array detector (VWR International, Wien, Austria, and Hitachi HTA, Schaumburg, Ill). Detector signals (absorbance at $214 \mathrm{~nm}$ and $254 \mathrm{~nm}$ ) were recorded and the program EZchrom Elite (VWR International) was used for data acquisition and analysis.
Energy charge was calculated as (ATP $+1 / 2$ ADP) (ATP + ADP + adenosine monophosphate). The pellets of the acid extract were dissolved in $1 \mathrm{~mL}$ of $0.1 \mathrm{~mol} / \mathrm{L}$ sodium hydroxide and diluted 1:10 with physiologic saline for protein determination (BCA Protein Assay; Thermo Fisher Scientific, Inc, Rockford, Ill).

\section{Histology}

Myocardial samples $(1 \times 1 \times 1 \mathrm{~mm})$ were cut with a surgical blade in a no-touch technique from a specimen collected from the mid-anterior wall of the left ventricle next to the LAD and preserved in buffer (4\% paraformaldehyde in $0.1 \mathrm{M}$ sodium cacodylate buffer) for electron microscopy. Electron microscopy was performed as described elsewhere. ${ }^{\mathrm{E} 3}$ Ultrastructural integrity was evaluated in samples from the left anterior wall with transmission electron microscopy using 3 randomly selected fields in a blinded manner per animal. Ischemic damage was graded according to the following scheme based on mitochondrial damage ${ }^{\mathrm{E} 3}$ : (0) no visible damage: normal matrix granules; (1) slight damage: loss of matrix granules, light clearing of matrix; (2) moderate damage: moderate clearing of matrix, moderate swelling and partial fragmentation of cristae; (3) severe damage: severe matrix clearing, severe swelling and loss of cristae; and (4) irreversible damage: amorphous dense granules. Representative micrographs of Grade 0 and Grade 2 are shown in Figure E4.

\section{MicroRNA (miRNA) Analysis}

Samples from the left anterior wall were stored at $-80^{\circ} \mathrm{C}$ before miRNAs analyses. Total RNA was extracted from homogenized heart tissue using the miRNeasy purification kit (QIAGEN, Hilden, Germany) and was quality checked for RNA integrity using the RNA 6000 bioanalyzer assay (Agilent, Carpinteria, Calif) and spectrophotometric RNA quantification (NanoDrop; Thermo Fisher Scientific, Inc). Equal amounts of total RNA (250 ng) were used for small RNA library preparation using the Clean-Tag ligation kit (TriLink, San Diego, Calif). Adapter-ligated libraries were amplified using barcoded Illumina reverse primers in combination with the Illumina forward primer. Libraries were pooled at equimolar rates on the basis of a DNA1000 bioanalyzer run (Agilent) and sent for sequencing to Exiqon (Vedbæk, Denmark). The small RNA library pool was sequenced on an Illumina NextSeq 500 with 50-bp cycle length. Reads were adapter trimmed and filtered for lowquality reads $(\mathrm{Q}<30)$. MiRNA annotation was performed on the basis of sequence alignments against the genome reference and miRBase release $21 .{ }^{\mathrm{E} 4}$ Read counts were normalized to the total number of reads detected per sample to obtain the "tags per million" for each miRNA and sample. Exploratory analysis was performed using ClustVis, ${ }^{\text {E5 }}$ and differential expression analysis was performed using 
the Edge $\mathrm{R}^{\mathrm{E} 6}$ package under R/Bioconductor. In addition, Mirnet (www.mirnet.ca) was used to analyze the intersection between experimentally verified targets of miR-122$5 \mathrm{p}$ and miR-708-5p. Based on the absence of specific data for Sus scrofa domesticus (pig), human data were used as reference. Subsequently, analysis for the assessment of proinflammatory cytokines (tumor necrosis factor-alpha, interleukin-6, and high mobility group box 1) and apoptosis (caspase-3) related genes was performed.

\section{Creatine Kinase-MB, Troponin-I, Lactate, Oxygen Consumption, and Malondialdehyde Assessment}

Arterial blood samples were drawn at baseline, 1, 5, 15, 30, $60,90,120$, and 150 minutes of reperfusion. During cardiopulmonary bypass, venous samples were drawn from the coronary sinus during controlled on-pump reperfusion: baseline, $1,5,15,30$, and 60 minutes of reperfusion. Immunoassays were performed for creatine kinase-muscle/brain (Cobas immunoassay CKL, ID 0-324; Roche, Bavaria, Germany) and troponin I (Immulite 1000 immunoassay; Siemens AG, Munich, Germany). Lactate was analyzed with blood gas measurements (ABL 800 flex; Drott, Wiener Neudorf, Austria).

Myocardial oxygen consumption was calculated using arterial oxygen content $\left(\mathrm{CaO}_{2}, \mathrm{~mL} \mathrm{O}_{2} / \mathrm{mL}\right)$ and coronary venous oxygen content $\left(\mathrm{CvO}_{2}, \mathrm{~mL} \mathrm{O} / \mathrm{mL}\right)$ : myocardial oxygen consumption $[\mathrm{mL} \mathrm{O} / \mathrm{min} / \mathrm{kg} \mathrm{BW}]=$ coronary flow/kg BW * $\left(\mathrm{CaO}_{2}-\mathrm{CvO}_{2}\right) / 100$ and for myocardial oxygen extraction: myocardial oxygen extraction $[\%]=\left(\mathrm{CaO}_{2}-\mathrm{CvO}_{2}\right) / \mathrm{CaO}_{2} * 100$.

Malondialdehyde (MDA) was determined in principal according to a previously described HPLC method by Pilz and colleagues ${ }^{\mathrm{E} 7}$ after derivatization with 2.4-dinitrophenylhydrazine (DNPH). In brief: For alkaline hydrolysis of protein-bound MDA, $25 \mu \mathrm{L}$ of $6 \mathrm{~mol} / \mathrm{L}$ sodium hydroxide was added to $0.125 \mathrm{~mL}$ of EDTA plasma (1.5 mL Eppendorf tubes) and incubated at $60^{\circ}$ (Eppendorf heater) for 30 minutes. The hydrolyzed sample was deproteinized with $62.5 \mu \mathrm{L} \mathrm{35 \%}$ (v/v) perchloric acid. Then, $125 \mu \mathrm{L}$ of supernatant obtained after centrifugation (14,000g; 2 minutes) was mixed with $12.5 \mu \mathrm{L}$ of DNPH solution and incubated for 10 minutes. This reaction mixture, diluted derivatized standard solutions (0.625$10 \mathrm{nmol} / \mathrm{mL}$ ), and reagent blanks were injected into the HPLC system (injection volume: $40 \mu \mathrm{L}$ ). The MDA standard was prepared by dissolving $25 \mu \mathrm{L}$ of 1.1.3.3-tetramethoxypropane in $100 \mathrm{~mL}$ of bi-distilled $\mathrm{H}_{2} \mathrm{O}$ (stock solution: $1 \mathrm{mmol} / \mathrm{L}$ ). The hydrolysis was performed with $200 \mu \mathrm{L}$ of 1.1.3.3-tetramethoxypropane stock solution in $10 \mathrm{~mL}$ of $1 \%$ sulfuric acid and incubation for
2 hours at room temperature. ${ }^{\mathrm{E} 8}$ The resulting MDA standard of $20 \mathrm{nmol} / \mathrm{mL}$ was further diluted with $1 \%$ sulfuric acid to the final concentrations. The DNPH derivates (hydrazones) were isocratically separated on a $5-\mu \mathrm{m}$ ODS hypersil column $(150 \times 4.6 \mathrm{~mm})$ guarded by a $5-\mu \mathrm{m}$ ODS hypersil column $(10 \times 4.6 \mathrm{~mm}$; Uniguard holder) with a mobile phase consisting of a $0.2 \%(\mathrm{v} / \mathrm{v})$ acetic acid solution (bidistilled water) containing 50\% acetonitrile $(\mathrm{v} / \mathrm{v})$. The HPLC separations were performed with an L-2200 autosampler, an L-2130 HTA pump, and an L-2450 diode array detector (all: VWR Hitachi; Vienna, Austria). Detector signals (absorbance at $310 \mathrm{~nm}$ ) were recorded and program EZchrom Elite (VWR) was used for data requisition and analysis. ${ }^{\mathrm{E}}$

\section{Quantitative Polymerase Chain Reaction (qPCR) Analysis}

RNA isolation. Tissues were homogenized in $750 \mu \mathrm{L}$ of Qiazol with TissueRuptor (QIAGEN) for 30 seconds at full speed. RNA extraction was performed with $140 \mu \mathrm{L}$ of chloroform, and phase separation was achieved by centrifugation for 15 minutes at $12,000 \mathrm{~g}$ at $4^{\circ} \mathrm{C}$. Then, $350 \mu \mathrm{L}$ of the upper aqueous phase were precipitated and purified on a QIAcube liquid-handling robot using the miRNeasy Mini Kit (QIAGEN). The aqueous phase was precipitated with $525 \mu \mathrm{L}$ of $100 \%$ ethanol and columns were washed with RWT and RPE buffer. Total RNA was eluted in a single round in $30 \mu \mathrm{L}$ of nuclease-free water and stored at $-80^{\circ} \mathrm{C}$.

mRNA qPCR quantification. From isolated total RNA, cDNA was synthesized using the TATAA GrandScript cDNA Synthesis Kit (TATAA Biocenter, Goteborg, Sweden). Reverse transcription reactions were performed in $20-\mu \mathrm{L}$ reactions with $500 \mathrm{ng}$ of total RNA. For each sample, qPCRs were performed in $10-\mu \mathrm{L}$ reactions in duplicates with $2 \mu \mathrm{L}$ of $1: 2$ diluted cDNA and $8 \mu \mathrm{L}$ of qPCR Mix consisting of $5 \mu \mathrm{L}$ of TATAA SYBR Grandmaster Mix (TATAA Biocenter), $0.8 \mu \mathrm{L}$ of forward and reverse primer $(10 \mu \mathrm{M})$, and $2.2 \mu \mathrm{L}$ of nuclease-free water. qPCR was performed on a Roche LightCycler 480 II instrument. The following thermocycling conditions were used: 30 seconds at $95^{\circ} \mathrm{C}, 45$ cycles of 5 seconds at $95^{\circ} \mathrm{C}, 15$ seconds at $63^{\circ} \mathrm{C}, 10$ seconds at $72^{\circ} \mathrm{C}$, followed by melting curve analysis. $\mathrm{Cq}$ values were computed using the second derivative maximum method provided with the LC480 II software. ACTB was used as a reference gene, and normalization was performed as follows: normalized $\mathrm{Cq}=\mathrm{Cq}^{\mathrm{ACTB}}-\mathrm{Cq}^{\mathrm{GOI}}$.

The following primers were used: 


\begin{tabular}{lll}
\hline \multicolumn{1}{c}{ Gene } & Forward primer & Reverse primer \\
\hline ACTB & CACGCCATCCTGCGTCTGGA & AGCACCGTGTTGGCGTAGAG \\
TNF alpha & GGCCCAAGGACTCAGATCAT & CTGTCCCTCGGCTTTGACAT \\
Interleukin-6 & ATGTCGAGGCTGTGCAGATT & TTGTGTTCTTCATCCACTCGT \\
HMGB1 & GGCTGCTAAGCTGAAGGAGA & GCTGCATCAGGCTTCCCTTT \\
CASP3 & TTGAGACGGACAGTGGGACT & CGTCCTTTGAATTTCGCCAGG \\
\hline
\end{tabular}

$A C T B$, Actin beta; $T N F$, tumor necrosis factor; $H M G B 1$, high mobility group box 1; CASP3, caspase 3 .

\section{E-References}

E1. Pelzmann B, Hallstrom S, Schaffer P, Lang P, Nadlinger K, Birkmayer GD, et al. NADH supplementation decreases pinacidil-primed I K ATP in ventricular cardiomyocytes by increasing intracellular ATP. Br J Pharmacol. 2003;139:749-54.

E2. Hallstrom S, Gasser H, Neumayer C, Fügl A, Nanobashvili J, Jakubowski A, et al. S-nitroso human serum albumin treatment reduces ischemia/reperfusion injury in skeletal muscle via nitric oxide release. Circulation. 2002;105:3032-8.

E3. Korn P, Kroner A, Schirnhofer J, Hallström S, Bernecker O, Mallinger R, et al. Quinaprilat during cardioplegic arrest in the rabbit to prevent ischemia-reperfusion injury. J Thorac Cardiovasc Surg. 2002;124:352-60.

E4. Kozomara A, Griffiths-Jones S. miRBase: annotating high confidence microRNAs using deep sequencing data. Nucleic Acids Res. 2014;42:D68-73.

E5. Metsalu T, Vilo J. ClustVis: a web tool for visualizing clustering of multivariate data using Principal Component Analysis and heatmap. Nucleic Acids Res. 2015; 43:W566-70.
E6. Robinson MD, McCarthy DJ, Smyth GK. edgeR: a bioconductor package for dif ferential expression analysis of digital gene expression data. Bioinformatics 2010;26:139-40.

E7. Pilz J, Meineke I, Gleiter CH. Measurement of free and bound malondialdehyde in plasma by high-performance liquid chromatography as the 2,4-dinitrophenylhydrazine derivative. J Chromatogr B Biomed Sci Appl. 2000;742: 315-25.

E8. Esterbauer H, Lang J, Zadravec S, Slater TF. Detection of malonaldehyde by high-performance liquid chromatography. Methods Enzymol. 1984;105: 319-28.

E9. Lamprecht M, Obermayer G, Steinbauer K, Cvirn G, Hofmann L, Ledinski G, et al. Supplementation with a juice powder concentrate and exercise decrease oxidation and inflammation, and improve the microcirculation in obese women: randomised controlled trial data. Br J Nutr. 2013; 110:1685-95. 


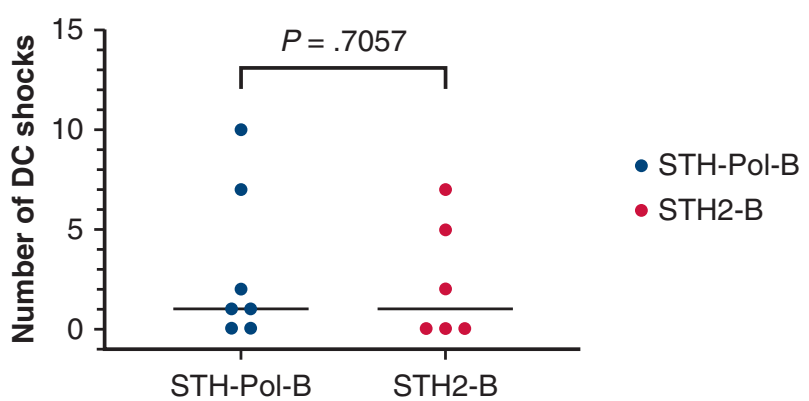

FIGURE E1. Number of direct current shocks at the beginning of reperfusion was comparable in both groups $(P=.071)$. $D C$, Direct current; $S T H$ Pol-B, new St Thomas' Hospital Polarizing blood cardioplegia; STH2-B, St Thomas' Hospital blood cardioplegia No. 2.

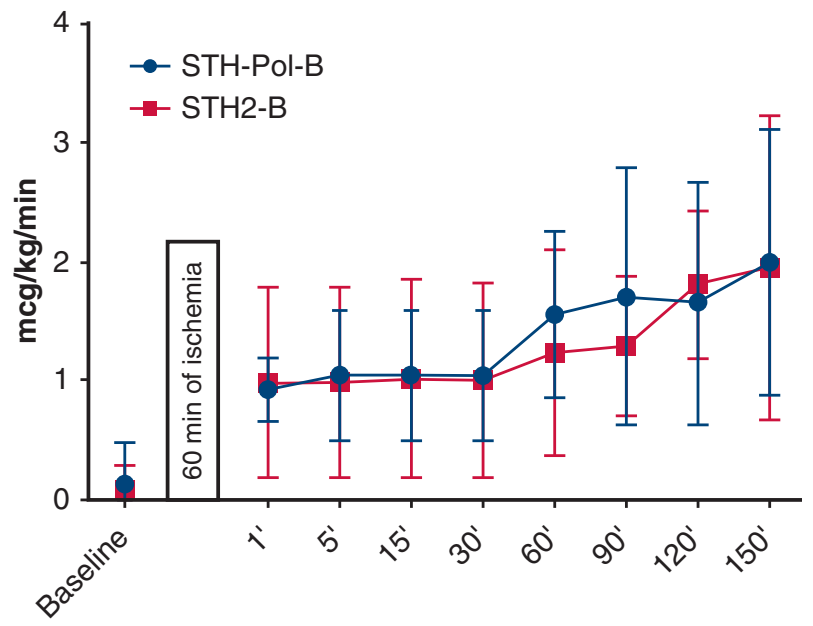

Time

FIGURE E2. To maintain systolic blood pressure $>70 \mathrm{~mm} \mathrm{Hg}$, continuous noradrenaline infusion was administered. Both groups demanded a similar amount of noradrenaline support during the experiment $(P=.702)$. STH-Pol-B, New St Thomas' Hospital Polarizing blood cardioplegia; $S T H 2-B$, St Thomas' Hospital blood cardioplegia No. 2.

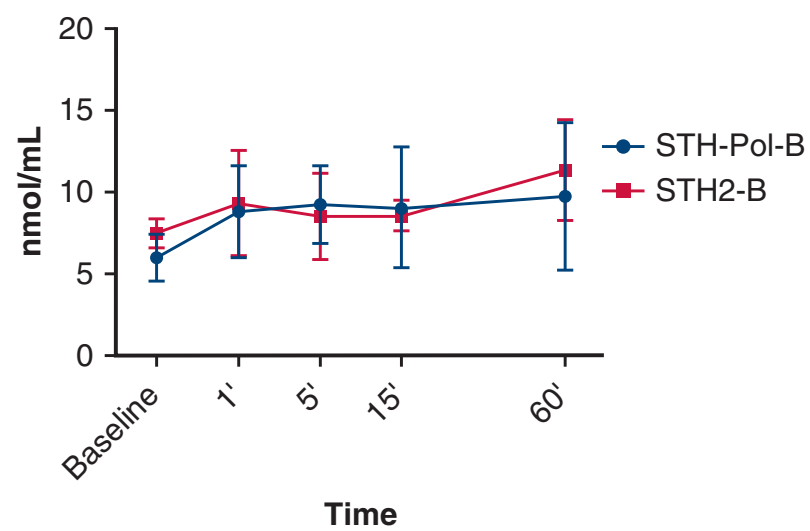

FIGURE E3. Arterial malondialdehyde plasma levels were comparable in both groups during on-pump reperfusion. STH-Pol-B, new St Thomas' Hospital Polarizing blood cardioplegia; STH2-B, St Thomas' Hospital blood cardioplegia No. 2 .
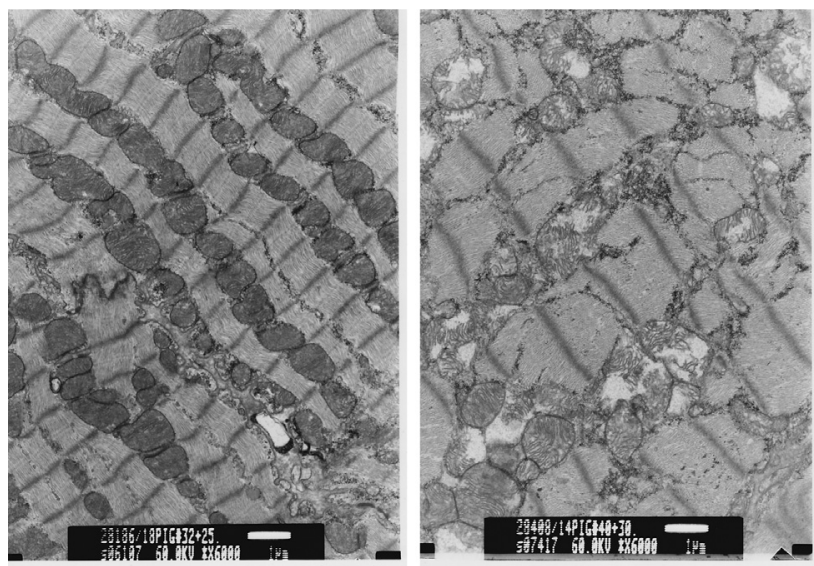

FIGURE E4. These representative micrographs show differences in grade of damage. On the left, no visible damage (grade 0: normal matrix granules) can be seen. on the right, moderate tissue damage (grade 2: moderate clearing of matrix. moderate swelling and partial fragmentation of cristae) can be detected. Transmission electron microscopy of samples obtained from the left anterior wall at the end of reperfusion. 


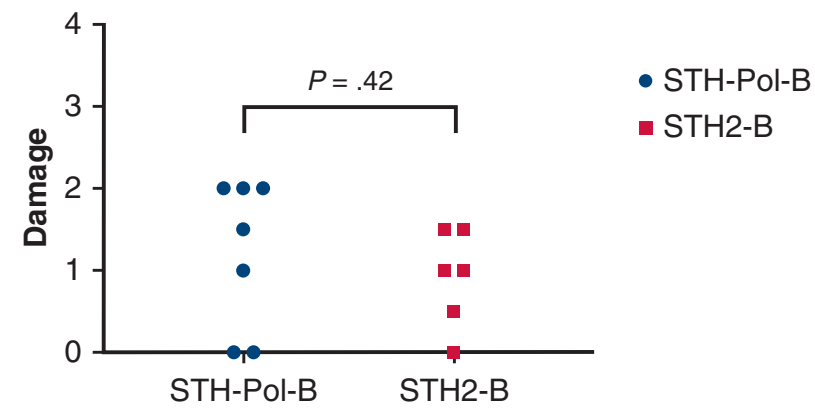

FIGURE E5. Ultrastructural integrity was evaluated in samples from the left anterior wall with transmission electron microscopy in each animal from 3 randomly selected fields in a blinded manner. None of the hearts in either group showed severe to irreversible damage. In STH-Pol-B, 2 samples showed no damage, 1 slight damage, 1 slight-to-moderate damage, and 3 moderate damage. In STH2-B, 1 sample showed no damage, 1 no to slight damage, 2 slight damage, and 2 samples showed slight-to-moderate damage, indicating similar protection with both cardioplegic solutions $(P=.42)$. STH-Pol- $B$, New St Thomas' Hospital Polarizing blood cardioplegia; STH2-B, St Thomas' Hospital blood cardioplegia No. 2.
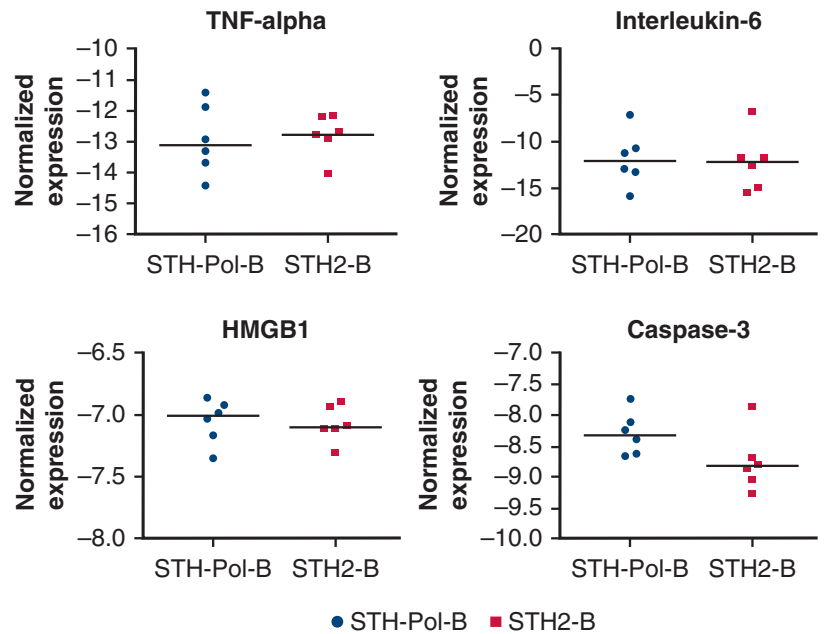

FIGURE E6. The anti-inflammatory miR-708-5p was significantly lower in STH-Pol-B. Consecutive assessment of proinflammatory cytokines (TNF-alpha, IL-6, and HMGB1) and apoptosis (caspase-3) related genes showed no differences between the groups. (TNF-alpha: $P=.78$; IL-6: $P=.85$; HMGB1: $P=.84$; caspase-3: $P=.09$ ). STH-Pol-B, new St Thomas' Hospital Polarizing blood cardioplegia; $T N F$, tumor necrosis factor; $I L$, interleukin; $H M G B 1$, high mobility group box 1 . 
TABLE E1. Final concentrations of cardioplegia components after 1:2 dilution (blood: crystalloid)

\begin{tabular}{lcc}
\hline Composition, mmol/L & STH-Pol-B & STH2-B \\
\hline Esmolol & 0.68 & - \\
Adenosine & 0.33 & - \\
Magnesium & 6.67 & 10.7 \\
Sodium chloride & 110 & 110 \\
Potassium chloride & 4 & 10.7 \\
Calcium chloride & 1.2 & 1.2 \\
\hline
\end{tabular}

Final molar concentrations in low-dose cardioplegic solutions (STH-Pol-B and STH2-B). The basic composition of STH-Pol-B was esmolol, adenosine, and magnesium gluconate. Pig blood was mixed with the crystalloid solution (STH-Pol-B or STH2-B) immediately before administration. STH-Pol-B, New St Thomas' Hospital Polarizing blood cardioplegia; STH2-B, St Thomas' Hospital blood cardioplegia No. 2.

TABLE E2. Baseline hemodynamics and echocardiographic data

\begin{tabular}{|c|c|c|c|}
\hline Group & STH-Pol-B $(n=7)$ & STH2-B $(n=6)$ & $P$ value \\
\hline $\mathrm{HR}, \mathrm{bpm}$ & $113 \pm 22$ & $101 \pm 8$ & .25 \\
\hline EF-baseline, $\%$ & $58 \pm 10$ & $63 \pm 5$ & .46 \\
\hline EF-R, \% & $63 \pm 21$ & $76 \pm 11$ & .36 \\
\hline FS-baseline, $\%$ & $31 \pm 7$ & $33 \pm 4$ & .50 \\
\hline FS-R, \% & $38 \pm 9$ & $43 \pm 8$ & .46 \\
\hline Systolic AP, mm Hg & $72 \pm 16$ & $77 \pm 13$ & .57 \\
\hline Diastolic AP, mm Hg & $42 \pm 11$ & $46 \pm 10$ & .60 \\
\hline MAP, $\mathrm{mm} \mathrm{Hg}$ & $55 \pm 15$ & $60 \pm 9$ & .48 \\
\hline RAP mean, $\mathrm{mm} \mathrm{Hg}$ & $6 \pm 5$ & $8 \pm 2$ & .35 \\
\hline Wedge, $\mathrm{mm} \mathrm{Hg}$ & $10 \pm 3$ & $11 \pm 3$ & .46 \\
\hline Systolic LVP, mm Hg & $77 \pm 16$ & $83 \pm 6$ & .40 \\
\hline LVESP, $\mathrm{mm} \mathrm{Hg}$ & $82 \pm 12$ & $79 \pm 13$ & .69 \\
\hline LVEDP, $\mathrm{mm} \mathrm{Hg}$ & $13 \pm 3$ & $15 \pm 3$ & .21 \\
\hline $\mathrm{CO} / \mathrm{hw}, \mathrm{mL} / \mathrm{g}$ & $20.4 \pm 3.3$ & $17.0 \pm 2.7$ & .07 \\
\hline $\mathrm{SV}, \mathrm{mL} / \mathrm{kg} / \mathrm{beat}$ & $188.8 \pm 54.0$ & $165.0 \pm 31.4$ & .40 \\
\hline EHW, $\mathrm{mL} / \mathrm{kg}^{*} \mathrm{~mm} \mathrm{Hg}$ & $1600 \pm 460$ & $1380 \pm 284$ & .37 \\
\hline $\mathrm{CF}, \mathrm{mL} / \mathrm{kg} / \mathrm{min}$ & $137 \pm 109$ & $131 \pm 68$ & .91 \\
\hline Hct, $\%$ & $6.9 \pm 2.2$ & $7.2 \pm 1.5$ & .81 \\
\hline $\mathrm{dp} / \mathrm{dt}_{\max }, \mathrm{mm} \mathrm{Hg} / \mathrm{s}$ & $1387 \pm 474$ & $1038 \pm 583$ & .26 \\
\hline $\mathrm{dp} / \mathrm{dt}_{\min }, \mathrm{mm} \mathrm{Hg} / \mathrm{s}$ & $-1666 \pm 1156$ & $-836 \pm 429$ & .13 \\
\hline
\end{tabular}

Baseline hemodynamic values were recorded before the initiation of cardiopulmonary bypass. Values were comparable in both groups. Values are given in mean \pm standard deviation. STH-Pol-B, New St Thomas' Hospital Polarizing blood cardioplegia; STH2-B, St Thomas' Hospital blood cardioplegia No. 2; HR, heart rate; $E F$, ejection fraction; $R$, reperfusion; $F S$, fractional shortening; $A P$, arterial pressure; $M A P$, mean arterial pressure; $R A P$, right atrial pressure; $L V P$, left ventricular pressure; $L V E S P$, left ventricular endsystolic pressure; $L V E D P$, left ventricular end-diastolic pressure; $C O$, cardiac output; $S V$, stroke volume per kg heart weight; $E H W$, external heart work; $C F$, coronary flow per kg heart weight; $H c t$, hematocrit of cardioplegia; $d p / d t_{\max }$, left ventricular contractility; $d p / d t_{\min }$, left ventricular contractility. 
TABLE E3. High-energy phosphates

\begin{tabular}{lccc}
\hline \multicolumn{1}{c}{ Group } & $\begin{array}{c}\text { STH-Pol-B } \\
(\mathbf{n}=\mathbf{7})\end{array}$ & $\begin{array}{c}\text { STH2-B } \\
(\mathbf{n}=\mathbf{6})\end{array}$ & $\boldsymbol{P}$ value \\
\hline Hypoxanthine, nmol/mg & $0.58 \pm 0.25$ & $0.93 \pm 0.73$ & .255 \\
AMP, nmol/mg & $0.96 \pm 0.34$ & $1.15 \pm 1.17$ & .677 \\
ADP, nmol/mg & $5.34 \pm 1.09$ & $5.85 \pm 1.84$ & .539 \\
ATP, nmol/mg & $28.57 \pm 7.88$ & $24.54 \pm 7.92$ & .359 \\
PCr, nmol/mg & $71.97 \pm 31.07$ & $64.60 \pm 40.74$ & .710 \\
Energy charge & $0.89 \pm 0.03$ & $0.88 \pm 0.03$ & .563 \\
\hline
\end{tabular}

At the end of the experiment, tissue samples were harvested from the left ventricular free wall for energy status analysis. There were no significant differences in levels of hypoxanthine, AMP, ADP, ATP, PCr, and energy charge between groups. STH-Pol-B, New St Thomas' Hospital Polarizing blood cardioplegia; $S T H 2-B$, St Thomas' Hospital blood cardioplegia No. 2; $A M P$, adenosine monophosphate; $A D P$, adenosine diphosphate; $A T P$, adenosine triphosphate, $P C r$, phosphocreatine.

TABLE E4. TPM for the top-regulated microRNAs identified by next-generation sequencing

\begin{tabular}{|c|c|c|c|c|c|}
\hline $\begin{array}{c}\text { Group } \\
\text { MicroRNA ID }\end{array}$ & STH-Pol-B, avg \pm SD & STH2-B, avg \pm SD & $\log 2 \mathrm{FC}$ & Expression level (log2 TPM) & $P$ value \\
\hline ssc-miR-708-5p & $26 \pm 13$ & $45 \pm 21$ & 0.78 & 5.15 & .019 \\
\hline ssc-miR-122 & $25 \pm 35$ & $10 \pm 8$ & -1.37 & 4.07 & .046 \\
\hline ssc-miR-369 & $144 \pm 22$ & $113 \pm 22$ & -0.35 & 7.01 & .066 \\
\hline ssc-miR-758 & $11 \pm 1$ & $8 \pm 2$ & -0.40 & 3.28 & .067 \\
\hline ssc-miR-338 & $32 \pm 10$ & $43 \pm 15$ & 0.41 & 5.24 & .11 \\
\hline ssc-miR-323 & $26 \pm 5$ & $21 \pm 4$ & -0.33 & 4.56 & .12 \\
\hline ssc-miR-144 & $289 \pm 132$ & $429 \pm 286$ & 0.57 & 8.49 & .12 \\
\hline ssc-miR-204 & $8 \pm 2$ & $12 \pm 7$ & 0.52 & 3.33 & .14 \\
\hline ssc-miR-450b-5p & $140 \pm 17$ & $119 \pm 13$ & -0.24 & 7.02 & .15 \\
\hline ssc-miR-490-5p & $60 \pm 3$ & $51 \pm 7$ & -0.23 & 5.80 & .16 \\
\hline ssc-miR-503 & $50 \pm 11$ & $41 \pm 7$ & -0.28 & 5.52 & .17 \\
\hline ssc-miR-132 & $21 \pm 6$ & $17 \pm 3$ & -0.31 & 4.23 & .17 \\
\hline ssc-miR-10b & $1083 \pm 266$ & $1363 \pm 425$ & 0.33 & 10.26 & .17 \\
\hline ssc-miR-182 & $234 \pm 76$ & $181 \pm 74$ & -0.37 & 7.70 & .21 \\
\hline ssc-miR-542-3p & $618 \pm 88$ & $539 \pm 40$ & -0.20 & 9.18 & .22 \\
\hline ssc-miR-450a & $23 \pm 3$ & $27 \pm 6$ & 0.25 & 4.64 & .24 \\
\hline ssc-miR-7134-5p & $95 \pm 10$ & $112 \pm 29$ & 0.24 & 6.69 & .24 \\
\hline ssc-miR-769-5p & $101 \pm 11$ & $88 \pm 12$ & -0.19 & 6.57 & .25 \\
\hline ssc-miR-149 & $73 \pm 14$ & $63 \pm 12$ & -0.23 & 6.09 & .26 \\
\hline ssc-miR-374a-5p & $1187 \pm 214$ & $1406 \pm 424$ & 0.24 & 10.34 & .27 \\
\hline ssc-let-7d-5p & $4011 \pm 413$ & $4514 \pm 446$ & 0.17 & 12.06 & .28 \\
\hline ssc-let-7f & $48,946 \pm 3873$ & $54,654 \pm 3815$ & 0.16 & 15.66 & .28 \\
\hline ssc-miR-125b & $754 \pm 54$ & $849 \pm 126$ & 0.17 & 9.65 & .29 \\
\hline ssc-miR-340 & $267 \pm 28$ & $237 \pm 29$ & -0.17 & 7.98 & .29 \\
\hline
\end{tabular}

Overall, 238 miRNAs were detected in all samples with a minimum abundance of 1 TPM. Table E4 provides a summary of next-generation sequencing results for the topregulated microRNAs $(P<.3)$ obtained by EdgeR, including the average (avg) expression levels (tags per million) together with standard deviation (SD), the fold change in expression between STH2-B and STH-Pol-B, as well as $P$ value. STH-Pol-B, New St Thomas' Hospital Polarizing blood cardioplegia; STH2-B, St Thomas' Hospital blood cardioplegia No. 2; TPM, tags per million. 
TABLE E5. Summarized endpoints

\begin{tabular}{|c|c|c|c|c|c|c|c|}
\hline \multirow{2}{*}{$\begin{array}{ll} & \text { Index } \\
\mathrm{HR} & \end{array}$} & \multicolumn{2}{|c|}{ time $\times$ group interaction } & \multicolumn{2}{|c|}{ Main effect of group } & \multicolumn{2}{|c|}{ Main effect of time } & \multirow{2}{*}{$\begin{array}{c}\text { Favors } \\
\text { Similar }\end{array}$} \\
\hline & $\mathrm{F}(7,44.7)=0.832$ & $P=.567$ & $F(1,10.0)=2.652$ & $P=.18$ & $\mathrm{~F}(7,33.7)=2.652$ & $P=.027$ & \\
\hline Systolic AP & $\mathrm{F}(2,11)=0.650$ & $P=.541$ & $F(1,9.8)=2.778$ & $P=.127$ & $\mathrm{~F}(2,11.4)=0.925$ & $P=.424$ & Similar \\
\hline Diastolic AP & $F(2,23.6)=2.649$ & $P=.092$ & $F(1,8.8)=6.519$ & $P=.032$ & $\mathrm{~F}(2,17.2)=8.638$ & $P=.003$ & STH-Pol-B \\
\hline MAP & $\mathrm{F}(2,22)=2.697$ & $P=.090$ & $F(1,10)=11.604$ & $P=.007$ & $\mathrm{~F}(2,12)=9.937$ & $P=.003$ & STH-Pol-B \\
\hline RAP mean & $\mathrm{F}(2,10.3)=2.296$ & $P=.149$ & $\mathrm{~F}(1,8.6)=1.238$ & $P=.296$ & $\mathrm{~F}(2,11.4)=1.346$ & $P=.299$ & Similar \\
\hline Systolic LVP & $\mathrm{F}(2,11.0)=0.522$ & $P=.607$ & $F(1,10)=25.609$ & $P=.000$ & $\mathrm{~F}(2,12.0)=3.088$ & $P=.083$ & STH-Pol-B \\
\hline SV & $\mathrm{F}(2,8.1)=0.141$ & $P=.870$ & $\mathrm{~F}(1,8)=9.471$ & $P=.015$ & $\mathrm{~F}(2,20)=10.953$ & $P=.001$ & STH-Pol-B \\
\hline $\mathrm{CO}$ & $F(2,10.4)=1.173$ & $P=.347$ & $\mathrm{~F}(1,9)=1.310$ & $P=.282$ & $\mathrm{~F}(2,13.6)=8.091$ & $P=.005$ & Similar \\
\hline EHW & $\mathrm{F}(2,9.3)=0.119$ & $P=.889$ & $F(1,7.9)=10.442$ & $P=.012$ & $\mathrm{~F}(2,10.3)=4.292$ & $P=.044$ & STH-Pol-B \\
\hline LVESP & $\mathrm{F}(2,11.0)=1.578$ & $P=.250$ & $\mathrm{~F}(1,10.0)=10.151$ & $P=.010$ & $\mathrm{~F}(2,12.0)=3.448$ & $P=.066$ & STH-Pol-B \\
\hline LVEDP & $\mathrm{F}(2,22)=2.959$ & $P=.073$ & $\mathrm{~F}(1,10)=0.735$ & $P=.411$ & $\mathrm{~F}(2,12)=0.796$ & $P=.474$ & Similar \\
\hline $\mathrm{CF}$ & $F(7,45.8)=0.692$ & $P=.678$ & $F(1,9.6)=6.467$ & $P=.030$ & $\mathrm{~F}(7,29.6)=2.031$ & $P=.084$ & STH-Pol-B \\
\hline Wedge & $\mathrm{F}(2,11.2)=1.834$ & $P=.205$ & $F(1,9.4)=8.996$ & $P=.014$ & $\mathrm{~F}(2,12.5)=0.582$ & $P=.573$ & STH-Pol-B \\
\hline $\mathrm{dp} / \mathrm{dt}_{\max }$ & $\mathrm{F}(2,22)=0.852$ & $P=.440$ & $\mathrm{~F}(1,10)=6.733$ & $P=.027$ & $\mathrm{~F}(2,24)=2.380$ & $P=.114$ & STH-Pol-B \\
\hline Noradrenaline & $\mathrm{F}(7,16.4)=0.951$ & $P=.496$ & $\mathrm{~F}(1,10.0)=0.155$ & $P=.702$ & $\mathrm{~F}(7,18.3)=3.354$ & $P=.018$ & Similar \\
\hline Arterial CK-MB & $\mathrm{F}(7.14 .9)=1.323$ & $P=.310$ & $F(1,9.9)=0.1288$ & $P=.283$ & $\mathrm{~F}(7,14.8)=26.050$ & $P=.000$ & Similar \\
\hline Coronary CK-MB & $\mathrm{F}(4,11.8)=0.393$ & $P=.810$ & $F(1,9)=4.693$ & $P=.058$ & $\mathrm{~F}(4,44)=26.965$ & $P=.000$ & Similar \\
\hline Arterial troponin-I & $\mathrm{F}(7,21.4)=2.061$ & $P=.093$ & $\mathrm{~F}(1,10)=0.415$ & $P=.534$ & $\mathrm{~F}(7,84)=135.786$ & $P=.000$ & Similar \\
\hline Malondialdehyde & $\mathrm{F}(4,10.2)=1.147$ & $P=.389$ & $F(1,4.3)=0.159$ & $P=.709$ & $\mathrm{~F}(4,12.1)=0.275$ & $P=.888$ & Similar \\
\hline Arterial lactate & $\mathrm{F}(7,17.4)=2.312$ & $P=.074$ & $F(1,8.5)=0.493$ & $P=.501$ & $\mathrm{~F}(7,18.2)=1.191$ & $P=.356$ & Similar \\
\hline Coronary lactate & $\mathrm{F}(4,25.5)=4.871$ & $P=.005$ & $\mathrm{~F}(1,10.1)=0.300$ & $P=.596$ & $\mathrm{~F}(4,25.5)=2.202$ & $P=.097$ & Similar \\
\hline Coronary pH & $\mathrm{F}(4,21.2)=5.640$ & $P=.003$ & $\mathrm{~F}(1,9.227)=7.572$ & $P=.022$ & $\mathrm{~F}(4,21.2)=1.905$ & $P=.147$ & Similar \\
\hline $\begin{array}{l}\text { Coronary venous } \\
\text { oxygen content }\end{array}$ & $\mathrm{F}(4,15.23)=1.259$ & $P=.328$ & $\mathrm{~F}(1,10)=4.160$ & $P=.069$ & $F(4,48)=2.561$ & $P=.050$ & Similar \\
\hline
\end{tabular}

$\overline{H R}$, Heart rate; $A P$, arterial pressure; $S T H$-Pol-B, new St Thomas' Hospital Polarizing blood cardioplegia; $M A P$, mean arterial pressure; $R A P$, right atrial pressure; $L V P$, left ventricular pressure; $S V$, stroke volume per kg heart weight; $C O$, cardiac output; $E H W$, external heart work; $L V E S P$, left ventricular end-systolic pressure; $L V E D P$, left ventricular enddiastolic pressure; $C F$, coronary flow; $d p / d t_{\max }$, left ventricular contractility; $C K-M B$, creatine kinase-muscle/brain. 